\title{
Insular Cortical Projections to Functional Regions of the Striatum Correlate with Cortical Cytoarchitectonic Organization in the Primate
}

\author{
Masanori Chikama, ${ }^{1}$ Nikolaus R. McFarland, ${ }^{2}$ David G. Amaral, ${ }^{3}$ and Suzanne N. Haber ${ }^{2}$ \\ ${ }^{1}$ Department of Neurological Surgery, University of Okayama Medical School, Okayama 700, Japan, 2Department of \\ Neurobiology and Anatomy, University of Rochester School of Medicine, Rochester, New York 14642, and ${ }^{3}$ Center for \\ Neuroscience, University of California Davis, Davis, California 95616
}

\begin{abstract}
We examined the striatal projections from different cytoarchitectonic regions of the insular cortex using anterograde and retrograde techniques. The shell and medial ventral striatum receive inputs primarily from the agranular and ventral dysgranular insula. The central ventral striatum receives inputs primarily from the dorsal agranular and dysgranular insula. Projections to the central ventral striatum originate from more posterior and dorsal insular regions than projections to the medial ventral striatum. The dorsolateral striatum receives projections primarily from the dorsal dysgranular and granular insula.

These results show that cytoarchitectonically less differentiated (agranular) insular regions project to the ventromedial "limbic" part of the ventral striatum, whereas more differenti-
\end{abstract}

ated (granular) insular regions project to the dorsolateral "sensorimotor" part of the striatum. The finding that the ventral "limbic" striatum receives inputs from less differentiated regions of the insula is consistent with the general principle that less differentiated cortical regions project primarily to the "limbic" striatum. Functionally, the ventral striatum receives insular projections primarily related to integrating feeding behavior with rewards and memory, whereas the dorsolateral striatum receives insular inputs related to the somatosensation. Information regarding food acquisition in the insula may be sent to the intermediate area of the striatum.

Key words: insular cortex; orbital and medial prefrontal cortex; cingulate cortex; gustation; limbic; paralimbic; association cortex
Corticostriatal projections are organized such that sensorimotor cortices project primarily to the dorsolateral striatum rostrally and to most of the putamen caudally, whereas structures associated with the limbic system project primarily to the ventral striatum (Künzle, 1975; Jones et al., 1977; Hemphill et al., 1981; Russchen et al., 1985; Selemon and Goldman-Rakic, 1985; Flaherty and Graybiel, 1991; Kunishio and Haber, 1994; Haber et al., 1995). The remainder of corticostriatal fibers terminate centrally between these two striatal regions, forming a dorsolateral-ventromedial continuum of terminal fields from sensorimotor, association, and limbic areas.

In primates, the ventral striatum includes the nucleus accumbens as well as the adjacent ventral caudate nucleus and putamen (Alheid et al., 1990; Haber et al., 1990). The ventral striatum is divided into shell and core regions. The shell region is distinguished from the core by its lack of calbindin- $\mathrm{D}_{28 \mathrm{k}}(\mathrm{CaBP})$ immunoreactivity and by its limited afferent projections (Martin et al., 1991; Kunishio and Haber, 1994; Haber et al., 1995; Giménez-Amaya et al., 1995; Meredith et al., 1996). In particular, the shell receives inputs primarily from agranular cortical areas including areas $24 \mathrm{a}$ and ventral $24 \mathrm{~b}$ of the cingulate cortex and areas 13a, 25, and 32 of the orbital and medial prefrontal cortex

Received May 5, 1997; revised Sept. 10, 1997; accepted Sept. 24, 1997.

This work was supported by National Institutes of Health (NIH) Grants NS22511 and MH45573 and a grant from the Lucille P. Markey Charitable Trust to S.N.H., NIH Grant MH11661-01 to N.R.M., and NIH Grants NS16980 and MH41479 to D.G.A.

Correspondence should be addressed to Dr. S. N. Haber, Department of Neurobiology and Anatomy, University of Rochester School of Medicine, 601 Elmwood Avenue, Rochester, NY 14642.

Copyright (C) 1997 Society for Neuroscience $0270-6474 / 97 / 179686-20 \$ 05.00 / 0$
(OMPFC). Based on our injection sites, we further subdivide the core into three areas: the medial, central, and lateral ventral striatal territories (see Fig. $2 A$ ). Although the adjacent medial ventral striatum receives inputs similar to that of the shell, it also receives more widespread projections (Giménez-Amaya et al., 1995; Haber et al., 1995). Cortical areas that project to the central and lateral ventral striatum receive inputs from cytoarchitectonically more differentiated (i.e., dysgranular) cortical regions, including areas $23 \mathrm{~b}$, dorsal $24 \mathrm{~b}$, and the lower bank of $24 \mathrm{c}$ of the cingulate cortex and areas 11, 12o, and $13(\mathrm{~m}, \mathrm{l})$ of the orbital cortex. In contrast, the dorsolateral striatum receives inputs primarily from granular cortical areas of the cingulate cortex such as the fundus of areas 24c and 23c (Dum and Strick, 1993; Kunishio and Haber, 1994; Haber et al., 1995).

The cytoarchitectonic differentiation of the cortex ranges from three-layered allocortex to six-layered isocortex with agranular and dysgranular cortices as transitional regions. Agranular cortex lacks layers II and IV and is composed of two or three cellular strata, whereas granular cortex contains distinct granule cell clusters in layers II and IV. The dysgranular cortex represents an intermediate stage in which layers II and IV are not clearly distinguished (Mesulam and Mufson, 1982a). The organization of cortical projections from both the cingulate cortex and the OMPFC to the striatum is related to their cytoarchitectonic differentiation. Agranular cingulate and OMPFC areas project primarily to the ventral striatum, whereas granular areas project primarily to the dorsolateral striatum (Vogt et al., 1987; Morecraft et al., 1992; Carmichael and Price, 1994). Cingulate and OMPFC areas that display cytoarchitectonic differentiation intermediate to agranular and granular cortex project to a wide ventral striatal area. 

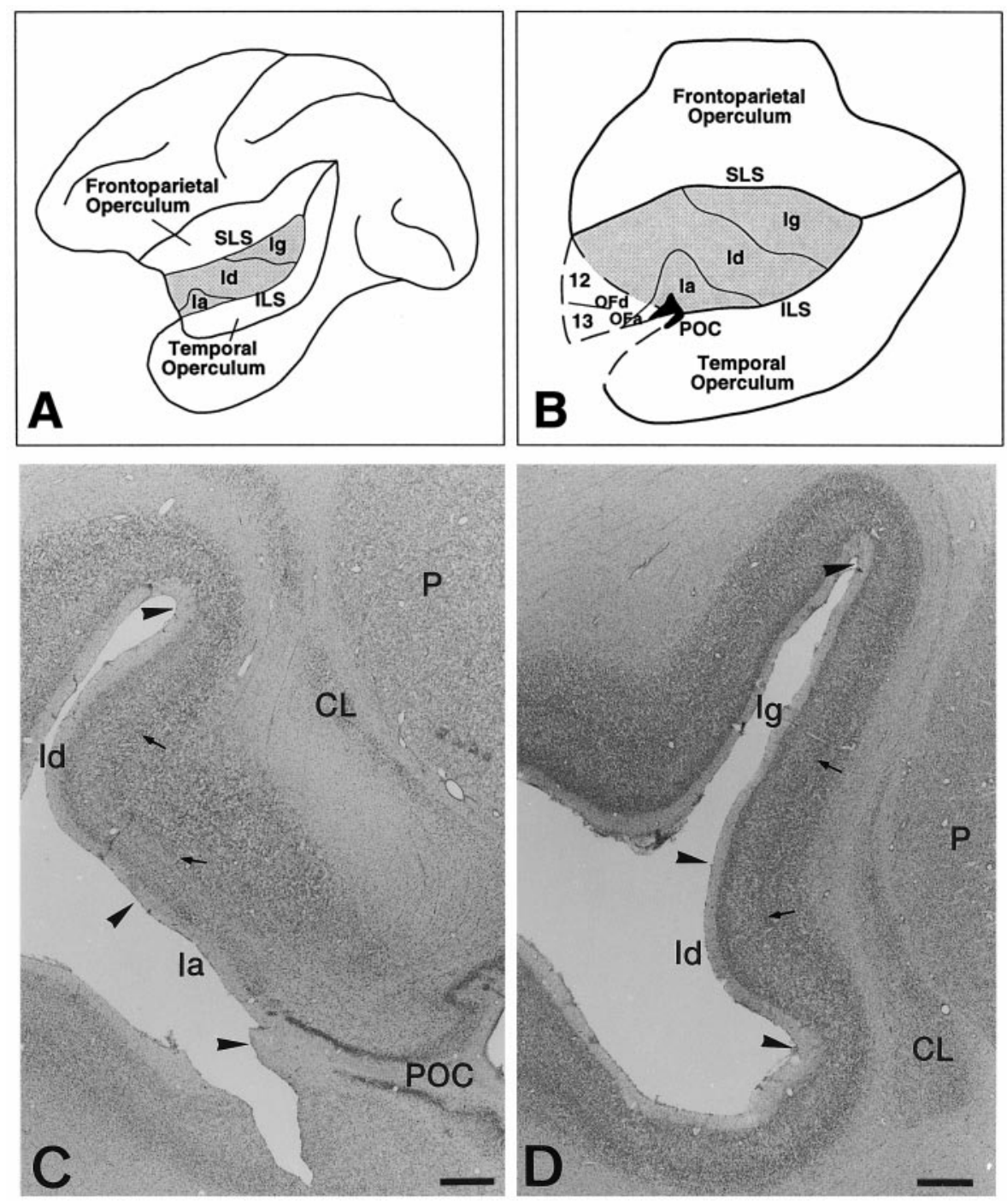

Figure 1. The cytoarchitectonic areas of the insula and surrounding regions. $A$, The insula is surrounded by the operculum after opening the lateral sulcus. The insular cortex is divided from the frontoparietal operculum by the SLS and the temporal operculum by the inferior limiting sulcus (ILS), respectively. B, Cytoarchitecture of the insula and surrounding regions. Shaded region represents the insula. The boundary between the anterior insular region and the posterior orbital region is not clear. Cytoarchitectonic divisions of the insula by Mesulam and Mufson (1982b). C, Photomicrograph of the insula at the level of the POC. Arrowheads mark the superior and inferior boundaries of the insula as well as the approximate zone of transition between the agranular and dysgranular regions. Small arrows indicate the granular cells in layer IV. Note that the agranular insula lacks layer IV. D, Photomicrograph of the posterior insula illustrating granular and dysgranular insular cortices (symbols indicate similar items). $C L$, Claustrum; $O F a$, agranular orbitofrontal cortex; $O F d$, dysgranular orbitofrontal cortex; $P$, putamen; $P O C$, piriform olfactory cortex. Scale bars, $1 \mathrm{~mm}$.
The insula is divided into three cytoarchitectonic areas (Fig. $1 A, B$ ), which are associated with different functions (Penfield and Faulk, 1955; Showers and Lauer, 1961; Friedman et al., 1986; Mesulam and Mufson, 1993; Schneider et al., 1993): (1) a rostroventral agranular insula (Ia) that is related to olfactory and autonomic functions, (2) an intermediate dysgranular insula (Id) that is associated with gustatory functions, and (3) a caudodorsal granular insula (Ig) that is associated with somatosensory, auditory, and visual functions. These three areas are arranged in a radial manner around the piriform olfactory cortex (POC) (Fig. $1 B)$. Like the cingulate cortex and the OMPFC, the insula has connections with both limbic and sensorimotor regions (Mufson and Mesulam, 1982; Mesulam and Mufson, 1982b; Amaral and Price, 1984; Friedman et al., 1986). We sought to determine whether the organization of striatal projections from the different cytoarchitectonic regions of the insula is related to different functional domains of the striatum. This would support the hypothesis that the organization of corticostriatal projections is in general related to the cytoarchitectonic differentiation of the cortex. For this purpose, we injected retrograde tracers into distinct regions of the ventral and dorsolateral striatum and anterograde tracers into the three cytoarchitectonic regions of the insula.

\section{MATERIALS AND METHODS}

Retrograde tracing study. Eleven adult macaque monkeys (Macacca nemestrina and M. mulatta) were used in these experiments. Initial anesthesia was administered by an intramuscular injection of ketamine $(10 \mathrm{mg} / \mathrm{kg})$. A deep surgical level of anesthesia was maintained by intravenous injection of phenobarbital (initial dose, $20 \mathrm{mg} / \mathrm{kg}$, i.v., and maintained as needed). Temperature, heart rate, and respiration were monitored throughout the surgery. Monkeys were placed in a Kopf stereotaxic apparatus, a midline scalp incision was made, and the muscle and fascia were displaced laterally to expose the skull. A craniotomy $\left(\sim 2-3 \mathrm{~cm}^{2}\right)$ was made over the region of interest, and small dural incisions were made only at recording or injection sites. Electrophysiological mapping was performed to locate appropriate injection sites as described earlier (Haber et al., 1990). Retrograde tracers, wheat germ agglutinin conjugated to horseradish peroxidase (WGA-HRP) (40-50 nl, 4\%; Sigma, St. Louis, MO), or Lucifer yellow (LY) conjugated to dextran amine (20-40 nl, 10\%; Molecular Probes, Eugene, OR), were pressure-injected over 10 min into discrete regions of the ventral and dorsolateral striatum using a $0.5 \mu \mathrm{m}$ Hamilton syringe. After the injection, the syringe remained in place for $20 \mathrm{~min}$ to prevent leakage up the needle track. After finishing tracer injections, the wound was closed in layers.

Monkeys were again deeply anesthetized 10-12 d later with phenobarbital and perfused through the heart with saline followed by a $4 \%$ paraformaldehyde including $1.5 \%$ sucrose solution in $0.1 \mathrm{M}$ phosphate buffer, $\mathrm{pH} 7.4,10-13 \mathrm{~d}$ after surgery. The brains were cryoprotected in increasing gradients of sucrose $(10,20$, and finally $30 \%)$. Serial sections 
$(50 \mu \mathrm{m})$ were cut on a sliding microtome and put into $0.1 \mathrm{M}$ phosphate buffer or stored in a cryoprotectant solution.

We used immunocytochemical techniques to visualize tracers. Before incubation with primary antiserum, tissue was incubated in a solution of $10 \%$ methanol and $3 \% \mathrm{H}_{2} \mathrm{O}_{2}$ in $0.1 \mathrm{M}$ phosphate buffer to inhibit endogenous peroxidases, followed by extensive rinsing with $0.3 \%$ Triton $\mathrm{X}-100$ in $0.1 \mathrm{M}$ phosphate buffer (PB-T), pH 7.4. Sections to be immunoreacted with anti-LY (Molecular Probes) or anti-WGA (Sigma) serum were then preincubated in $10 \%$ normal goat serum (NGS) diluted with PB-T (NGS-PB-T) for $30 \mathrm{~min}$. The tissue was placed in the primary antiserum, anti-LY diluted 1:1000 or anti-WGA-HRP diluted 1:2000 in NGS-PB-T for four nights at $4^{\circ} \mathrm{C}$. The avidin-biotin reaction (rabbit Vectastain ABC kit; Vector Laboratories, Burlingame, CA) was used to visualize the LY and WGA. The tissue was rinsed in PB-T before incubating in biotinylated goat anti-rabbit 1:400 NGS-PB-T at room temperature for $45 \mathrm{~min}$. After rinsing, the tissue was incubated in the rabbit avidin-biotin complex $(1: 200)$ at room temperature for $1 \mathrm{hr}$. Antisera binding was visualized by incubating the tissue for $10-12 \mathrm{~min}$ in a solution of $0.05 \%$ 3,3'-diaminobenzidine tetrahydrochloride (DAB) and $0.01 \% \mathrm{H}_{2} \mathrm{O}_{2}$ in a $0.5 \mathrm{M}$ Tris buffer. After several rinses, staining was intensified by incubating the tissue in the DAB solution described above with $0.025 \%$ cobalt chloride and $0.02 \%$ nickel ammonium sulfate to yield a black reaction product. After thorough rinsing, sections were mounted onto gel-coated slides and counterstained with cresyl violet using a standard Nissl procedure.

To determine whether the injection site was within the CaBP-negative shell region, sections containing the injection site were double-stained for $\mathrm{CaBP}$ and the tracer. Immunocytochemistry for the tracer was performed first, as described above. After thorough rinsing, tissue was preincubated in NGS-PB-T for $30 \mathrm{~min}$, and then placed in CaBP-antisera (monoclonal, Sigma) diluted 1:10,000 in NGS-PB-T for four nights at $4^{\circ} \mathrm{C}$. Visualization of CaBP-immunoreactivity was done using the avidin-biotin reaction (mouse Vectastain ABC kit, Vector) as described above. After rinsing, the tissue was stained with DAB (see above) to yield a brown reaction product. Sections were then rinsed, mounted on gelcoated slides, dehydrated, defatted, and coverslipped. Thus, in doublestained sections, tracers could be identified by a black stain and CaBP by its brown stain.

Anterograde tracing study. Five adult macaque monkeys ( $M$. fascicularis) were used in these experiments. Initial anesthesia was administered by an intramuscular injection of ketamine $(8 \mathrm{mg} / \mathrm{kg})$. Animals either were placed on a mechanical ventilator and brought to a surgical level of anesthesia with isoflurane or were anesthetized with nembutal (25 mg/ $\mathrm{kg}$, i.p.) and supplemented as necessary through a venous catheter throughout the surgery. The animals were mounted in a Kopf stereotaxic apparatus: a midline incision was made in the scalp, the dorsal skull was exposed, and the fascia and temporal muscles were displaced laterally. A craniotomy $\sim 1.5 \mathrm{~cm}^{2}$ was made, and the dura was reflected. The coordinates for the intended injection locations were based on the atlas by Szabo and Cowan (1984). In addition, electrophysiological mapping was performed to locate appropriate injection sites. For the tritiated amino acid injections, a glass micropipette was lowered to the insular cortex and a $1: 1$ solution of $\left[{ }^{3} \mathrm{H}\right]$ leucine and $\left[{ }^{3} \mathrm{H}\right]$ proline $(100 \mathrm{nl}$, concentrated to 100 $\mathrm{mCi} / \mathrm{ml}$ ) was ejected by air pressure as described by Amaral and Price (1983). After the tracer was placed at the intended location, the wound was closed in layers.

After a 2 week survival period, animals were deeply anesthetized and perfused intracardially with one of two fixative solutions: (1) pH-shift fix: $0.9 \% \mathrm{NaCl} ; 0.1 \mathrm{M} \mathrm{Na}$ acetate buffer with $4 \%$ paraformaldehyde, $\mathrm{pH} 6.5$; 0.1 M Na borate buffer with $4 \%$ paraformaldehyde, $\mathrm{pH} 9.5$; or (2) modified immunohistochemistry fix: $1 \%$ paraformaldehyde in $0.1 \mathrm{M} \mathrm{PO}_{4}$, $\mathrm{pH} \mathrm{7.2;} 4 \%$ paraformaldehyde in $0.1 \mathrm{M} \mathrm{PO}_{4}, \mathrm{pH} 7.2$. The brain was transferred to a solution of $2 \%$ DMSO and $20 \%$ glycerol in $0.1 \mathrm{M} \mathrm{PO}_{4}$ for $3 \mathrm{~d}$ and then frozen in cold isopentane and stored at $-70^{\circ}$ until cut. The frozen tissue was sectioned coronally at a thickness of $30 \mu \mathrm{m}$. A one-ineight series of sections was collected in $10 \%$ solution of formalin in $0.1 \mathrm{M}$ $\mathrm{PO}_{4}, \mathrm{pH}$ 7.2. The tissue was mounted onto gelatin-coated slides and processed for autoradiographic demonstration of labeled fibers and terminals according to the method of Cowan et al. (1972). Briefly, slides were dipped in emulsion (type NTB2; Eastman Kodak, Rochester, NY), dried, and exposed in the dark, at $4^{\circ} \mathrm{C}$, for 10 weeks. Slides were then developed for 2 min (D-19, Kodak), rinsed gently in distilled $\mathrm{H}_{2} \mathrm{O}$, fixed for 8 min (Polymax, 25\% solution, Kodak), rinsed again, and stained by the Nissl method with thionin.

Charting. Retrogradely labeled cells in the insula were charted using a light microscope fitted with a drawing tube. Similarly, dark-field microscopy was used to chart silver grain deposits over labeled terminals in the striatum after injection of tritiated amino acids into the insula. With the aid of a drawing tablet, charts were traced into a Power Macintosh computer to create composite images. Using Nissl-stained coronal sections, we determined the boundaries of cytoarchitectonic subdivisions of the insula as described by Mesulam and Mufson (1982b) (Fig. 1). The border between the anterior insula and the posterior orbital cortex is not easily differentiated. Like the agranular insula, the posterior orbital region lacks granular layers II and IV and lies superficial to the claustrum. Some investigators have proposed that the agranular insula extends into the posterior orbital region and that this orbital region therefore belongs to the agranular insula (Rose, 1928; Amaral and Price, 1984; Carmichael and Price, 1994). Although we have classified this area as a part of the orbitofrontal agranular area according to the description by Mesulam and Mufson (1982b), other orbitofrontal cortical areas have been divided by the classifications of Amaral and Price (1984) or Carmichael and Price (1994). For each retrograde experiment, the distribution of labeled cells was charted in the different insular territories including the adjacent posterior orbital cortex.

\section{RESULTS}

\section{Insular cortical projections to the striatum: retrograde studies}

To investigate the distribution of insulostriatal projections, we injected the retrograde tracers LY or WGA-HRP into 11 different regions of the striatum (Fig. 2). Nine injection sites are in the ventral striatum, including the shell of the nucleus accumbens (cases MS35, MS72, and MS74), the medial ventral striatum (cases MS14 and MS43), the central ventral striatum (cases MS6 and MS49), and the lateral ventral striatum (cases MS53 and MS73). Two injection sites are in the dorsolateral striatum. One is in the caudal and ventral portion of the putamen (case MS51). This striatal region receives inputs from the hand and face areas of sensorimotor cortex. The other is an injection into the rostral and dorsal portion of the putamen (case MS56). This area receives projections from the arm and leg areas of sensorimotor cortex (Künzle, 1975; Jones et al., 1977; Flaherty and Graybiel, 1991).

After injections of retrograde tracers into these distinct regions, labeled neurons were charted in the different cytoarchitectonic areas of the insula. Labeled cells are found bilaterally in the insula in all cases; however, only a few cells are labeled in the contralateral insula.

\section{Projections to the shell of the nucleus accumbens}

Case MS35 has an injection of WGA-HRP into the shell of the nucleus accumbens as identified by its lack of $\mathrm{CaBP}$ immunoreactivity. In general, there are many labeled cells located primarily in Ia and the ventral portion of Id (Fig. 3). The densest concentration is observed at rostral levels (Fig. 3A,B). Labeled cells are found primarily in the outer stratum of Ia or layer III of Id and extend into the adjacent region of the orbitofrontal cortex. At central levels, there are a few labeled neurons in Ia and in the ventral portion of Id (Fig. 3D-G); however, here they are found primarily in layer $\mathrm{V}$. No labeled neurons are found in the caudal portion of the insula (Fig. 3H). Case MS72 (data not shown) has an injection of WGA-HRP into the medial portion of the shell. In general, the distribution of labeled cells is similar to that in case MS35; however, labeled cells are found primarily in the inner stratum of Ia or layer V of Id throughout all levels. Case MS74 has a small injection of WGA-HRP into the medioventral portion of the shell. Scattered labeled cells are found in the rostral portion of Ia and the adjacent region of the orbitofrontal cortex (Fig. $4 A, B)$. Unlike in case MS35, labeled cells are found in the inner stratum of the rostral Ia, and no labeled cells are observed in either the ventral part of Id or the central and caudal parts of Ia. 

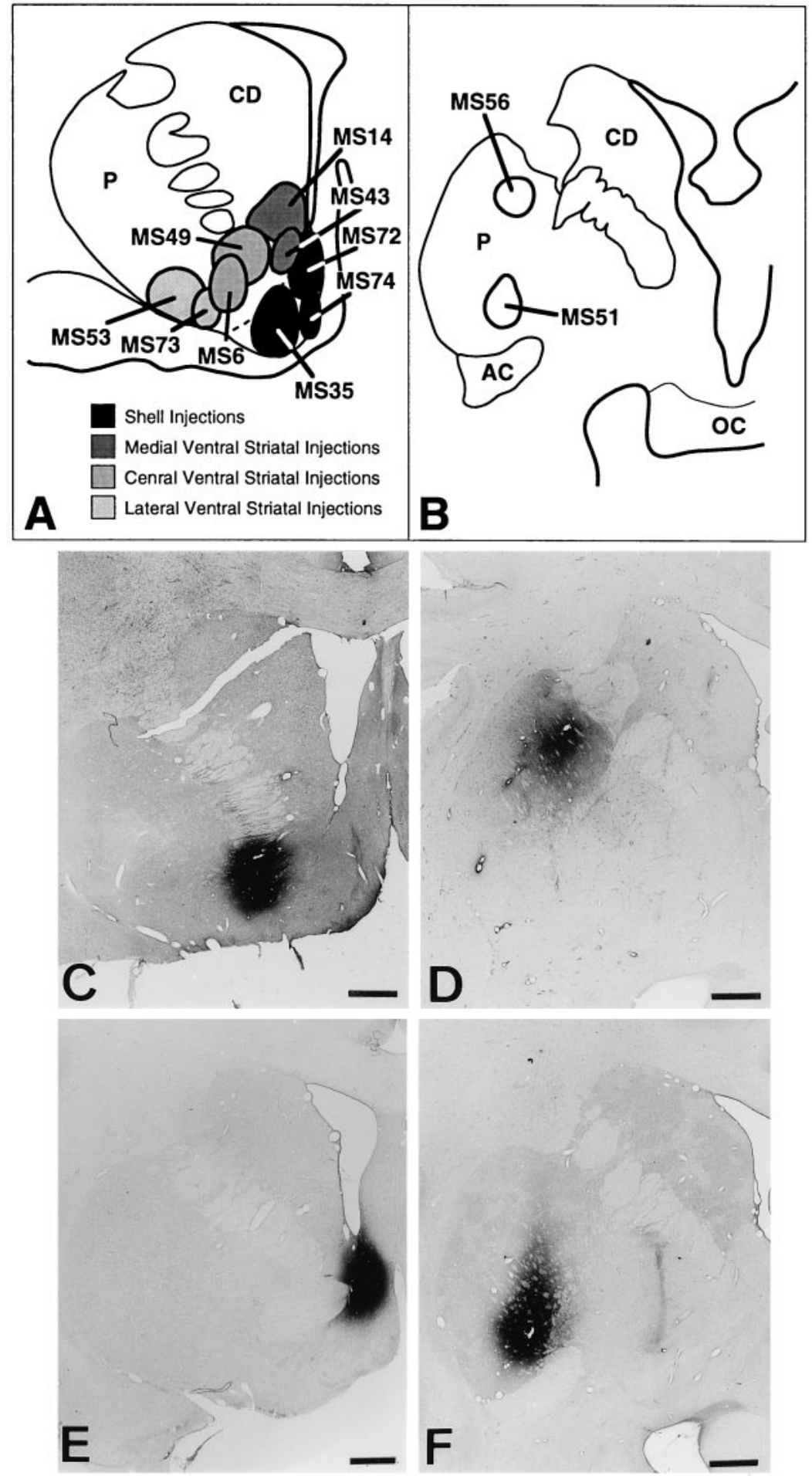

Figure 2. Coronal sections of the striatum illustrating injection sites of retrograde tracers. $A$, Nine different injection sites in the ventral striatum. The shell of the nucleus accumbens is CaBP-negative (ventromedial region bounded dorsally by dotted line). $B$, Two injection sites within the dorsolateral striatum. $C-F$, Photomicrographs of representative injection sites. $C$, Case MS6; $D$, case MS56; $E$, case MS72. $F$, Case MS51. $C D$, Caudate nucleus; $P$, putamen; $A C$, anterior commissure; $O T$, optic tract. Scale bars, $2 \mathrm{~mm}$.

\section{Projections to the medial ventral striatum}

Cases MS14 and MS43 have injections of WGA-HRP into the medial ventral striatum. This area is CaBP-positive and can be distinguished from the shell of the nucleus accumbens. As in the cases described above, retrogradely labeled neurons are also seen primarily in Ia and the ventral portion of Id at rostral levels (Figs. $5 A-C, 6$ ). In particular, the highest number of labeled cells is observed in the most rostral Ia and the adjacent caudal portion of the orbitofrontal cortex (Figs. 5A,B,6). In the central portion of the insula, there are scattered labeled neurons in Ia and the ventral portion of Id (Fig. $5 D-F$ ). At caudal levels, a few labeled neurons are found in the ventral portion of Id. There are no labeled neurons in Ig (Fig. 5G,H). Labeled cells throughout Id are found more dorsally than cells observed in cases of injections into the shell (MS35 and MS72). In contrast to an injection into the shell (MS35) demonstrating that labeled cells are found in the outer stratum of Ia or layer III of Id at the rostral level, almost all labeled neurons are found in the inner stratum of Ia or layer V of Id throughout all levels in these cases. The greatest concentration of cells is found in the rostral portion of both Ia and the ventral portion of Id (see Fig. 15B). 

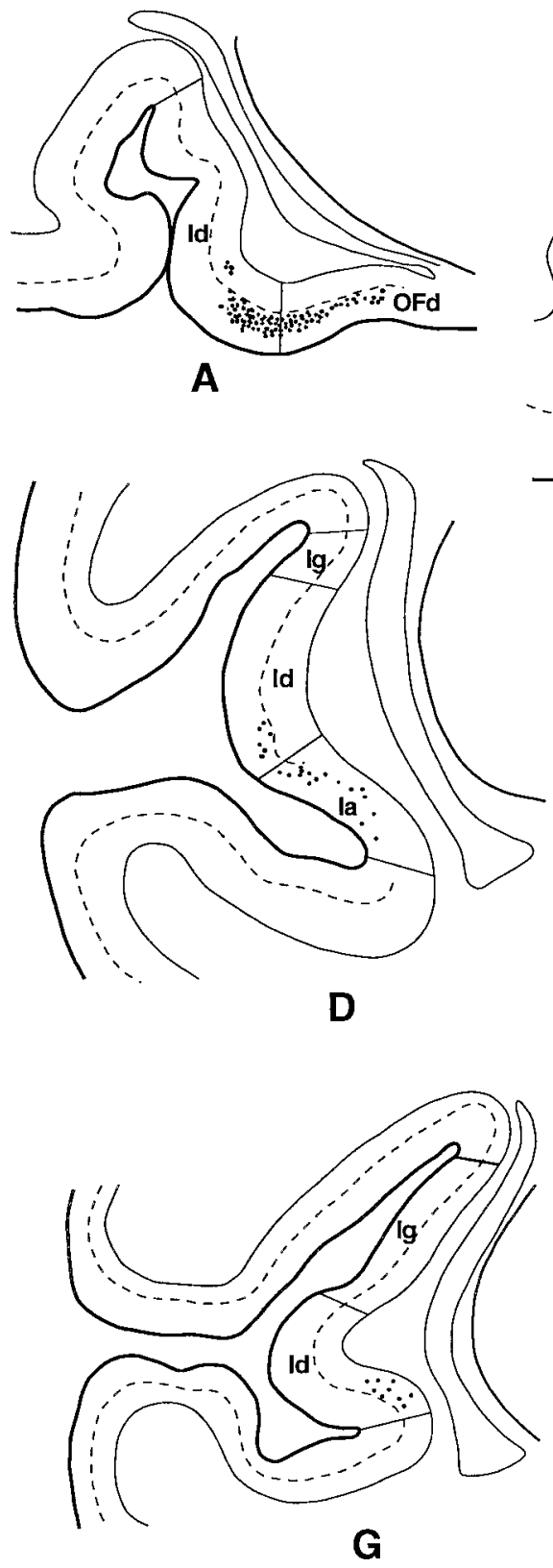
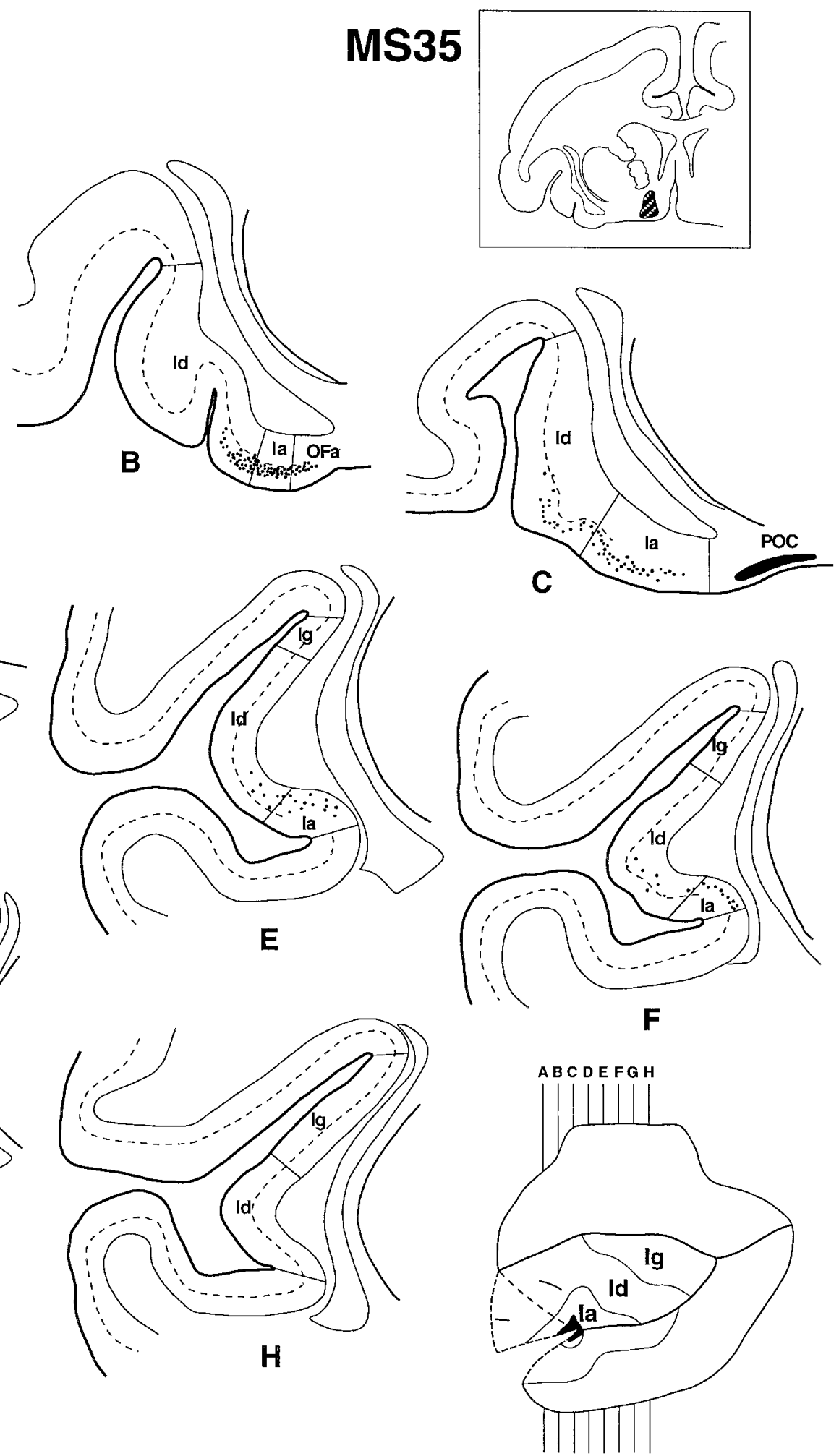

Figure 3. Schematic chartings of the distribution of retrogradely labeled cells in the insula after injection of WGA-HRP into the shell of the nucleus accumbens (case MS35). $A-H$, Serial coronal sections through the insula (rostral-caudal), each $1.2 \mathrm{~mm}$ apart. Dashed lines represent the boundary between layers IV and V. Each $d o t$ represents one labeled cell. $O F a$, Agranular orbitofrontal cortex; $O F d$, dysgranular orbitofrontal cortex; $P O C$, piriform olfactory cortex.

\section{Projections to the central ventral striatum}

Case MS49 has an injection of LY into the central ventral striatum. The injection site does not involve the shell. However, it does involve parts of the ventral and central caudate nucleus and the ventromedial putamen. There are numerous labeled cells in Ia and Id, and the densest distribution of labeled neurons is found in the rostroventral portion of Id. There are no labeled cells in Ig (see Fig. 15C). In the rostral portion of the insula, labeled neurons 


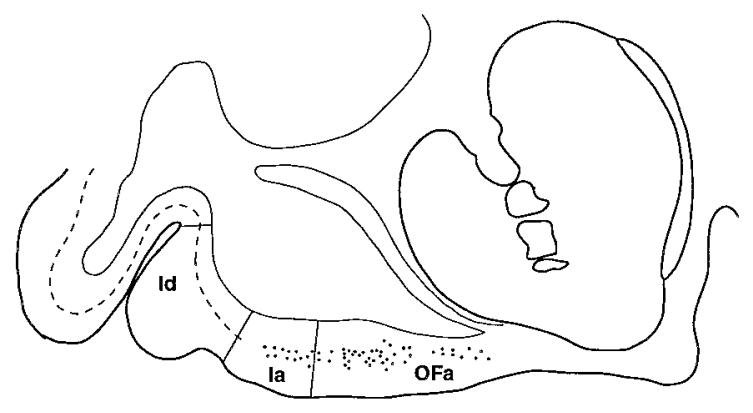

MS74

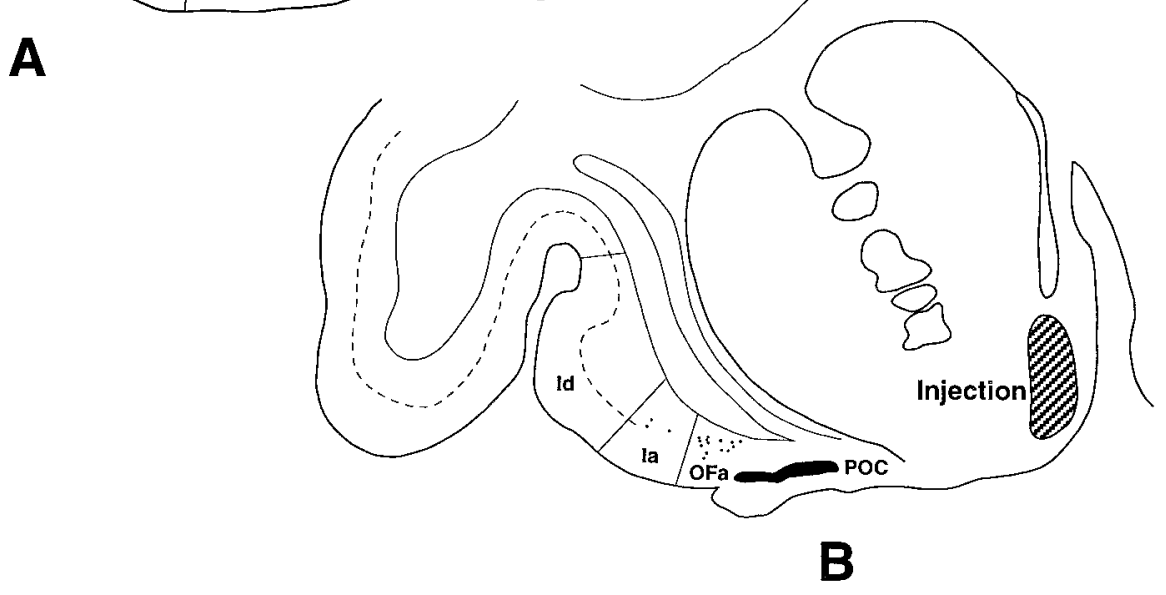

Figure 4. Schematic chartings of the distribution of the retrogradely labeled cells in the insular cortex after small injection of WGA-HRP into the shell of the nucleus accumbens (case MS74) at the level of the caudal agranular insula $(A)$ and at the level of the POC $(B)(1.2 \mathrm{~mm}$ caudal to $B)$. Dashed lines represent the boundary between layers IV and V. Each dot represents one labeled cell. $O F a$, Agranular orbitofrontal cortex; $O F d$, dysgranular orbitofrontal cortex; $P O C$, piriform olfactory cortex.

are distributed widely in Ia and Id, including the adjacent orbitofrontal cortex (Figs. $7 A, B, 8$ ). A dense population of labeled neurons is found in the ventral and central portions of Id. Although these neurons are found primarily in layer $\mathrm{V}$, a few labeled cells are also observed in layer III. At the central level, a moderate number of labeled neurons are found throughout Ia and Id except for in the most dorsal portion of Id (Fig. $7 C-F$ ). Most cells are seen in layer $\mathrm{V}$. In the caudal portion of the insula, there are scattered labeled cells in layer V of Id (Fig. 7G,H). Case MS6 (data not shown) has an injection of WGA-HRP into the ventral medial putamen. In general, the distribution of labeled neurons is similar to those in case MS49; however, no labeled cells are found in the ventral Ia or dorsal Id. Moreover, there are only a few labeled neurons in the caudal Id.

\section{Projections to the lateral ventral striatum}

Cases MS53 and MS73 have injections of LY into the lateral ventral striatum. In general, there are fewer labeled neurons in these cases. Labeled cells are found primarily in Id (see Fig. 15D). In the rostral and central portions of the insula, scattered labeled cells are found in both layers III and V of Id. There are very few labeled cells in Ia. Caudally, there are several labeled cells in Id. Only a few cells are found in Ig. Labeled neurons are seen primarily in layers $\mathrm{V}$ and VI.

\section{Projections to the dorsolateral striatum}

Case MS51 has an injection of WGA-HRP into the caudal and ventral portion of the dorsolateral striatum. There are some labeled neurons throughout Id and Ig, with a few labeled cells in Ia (Fig. 9A-H). At the rostral level, some WGA-HRP-positive neurons are found in Id and the dorsal portion of Ia (Fig. 9A,B), whereas in the central portion, more labeled neurons are observed in Id and Ig (Figs. 9C-F, 10). Caudally, few labeled neurons are concentrated in Id and $\operatorname{Ig}($ Fig. 9G,H). WGA-positive cells are seen primarily in layers V and VI throughout Id and Ig.
Case MS56 has an injection of LY into the rostral and dorsal portion of the dorsolateral striatum. There are scattered labeled cells in Ig and the dorsal portion of Id, especially in the posterior portion of the insula (Fig. $11 A-H$; also see Fig. $15 F$ ). Rostrally, there are no labeled neurons in Ia and Id (Fig. $11 A, B$ ). At central and caudal levels, a few labeled cells are found in Ig and the dorsal portion of Id, but no labeled cells are observed in the ventral portion of Id (Fig. $11 C-H$ ). Labeled cells are primarily in layers $\mathrm{V}$ and $\mathrm{VI}$ throughout Id and Ig.

\section{Insular cortical projections to the striatum: anterograde studies}

To examine further the organization of insular projections to the striatum, injections of tritiated amino acids were placed into discrete regions of the insula. The distribution of silver grains representing labeled terminals and fibers within the striatum was examined. The results from injections into the three cytoarchitectonic areas of the insula are described. Case M1-89 represents a large injection of tritiated amino acids into the central part of Ia, including the adjacent ventral portion of Id. Case M8-93 is centered in the central part of the anterior Id. The third injection, case M9-94, is located in the dorsal part of Ig. The area of each of these injection sites encompasses all layers of the cortex and does not extend into the adjacent claustrum.

\section{Agranular insular cortical projections (case M1-89)}

There are dense deposits of silver grains in a large anteroventral striatal region (Fig. 12), including primarily the ventral half of the head of the caudate nucleus and the rostroventral portion of the putamen. The distribution of the silver grains is patchy, with densely labeled areas surrounded by little or no specific labeling. At rostral levels (Fig. 12A-E), there is labeling primarily in the ventral portion of the caudate nucleus including the medial ventral striatum and the central ventral striatum. Although the shell contains some scattered patches of silver grains, the density is 

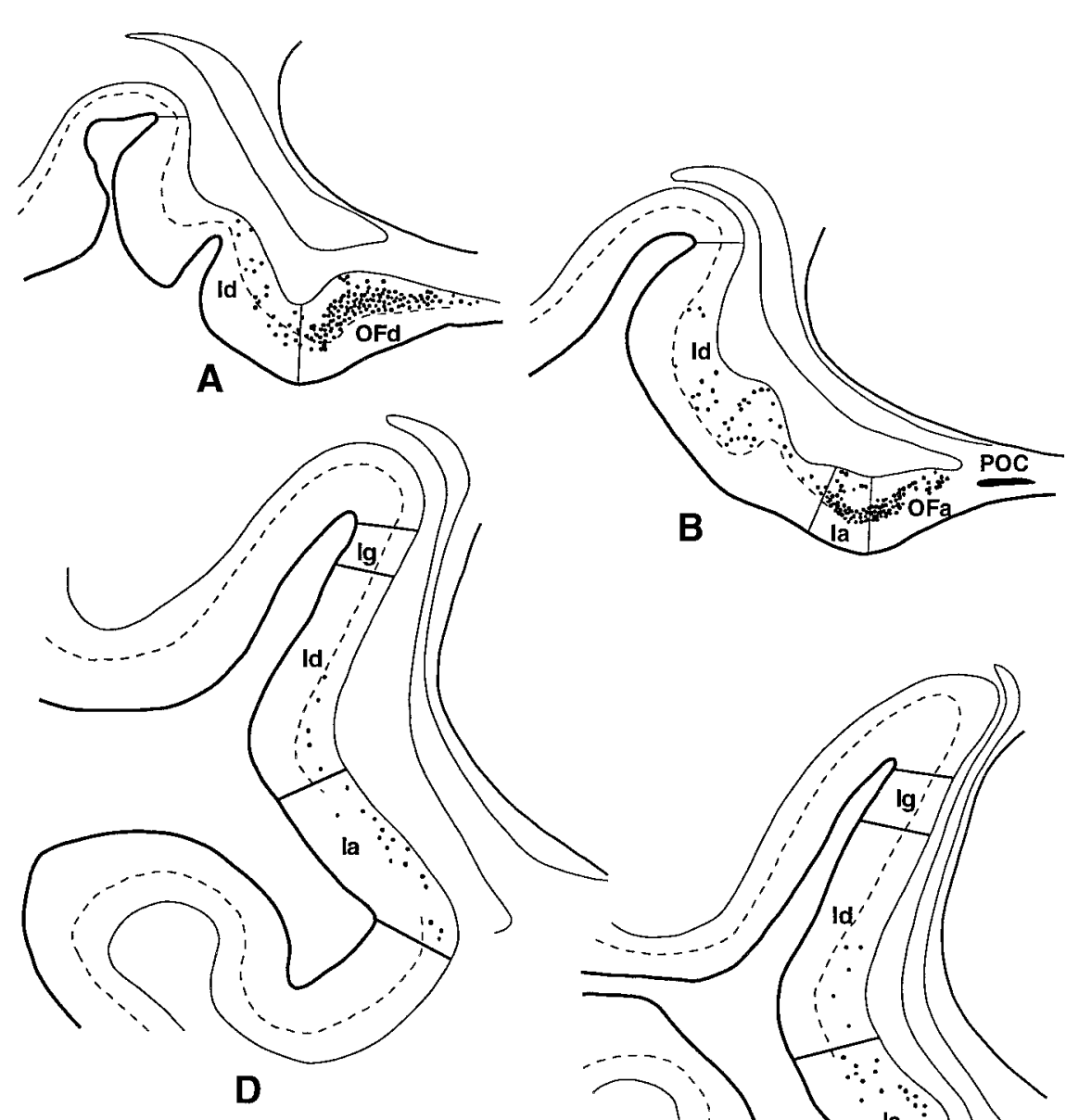

MS14
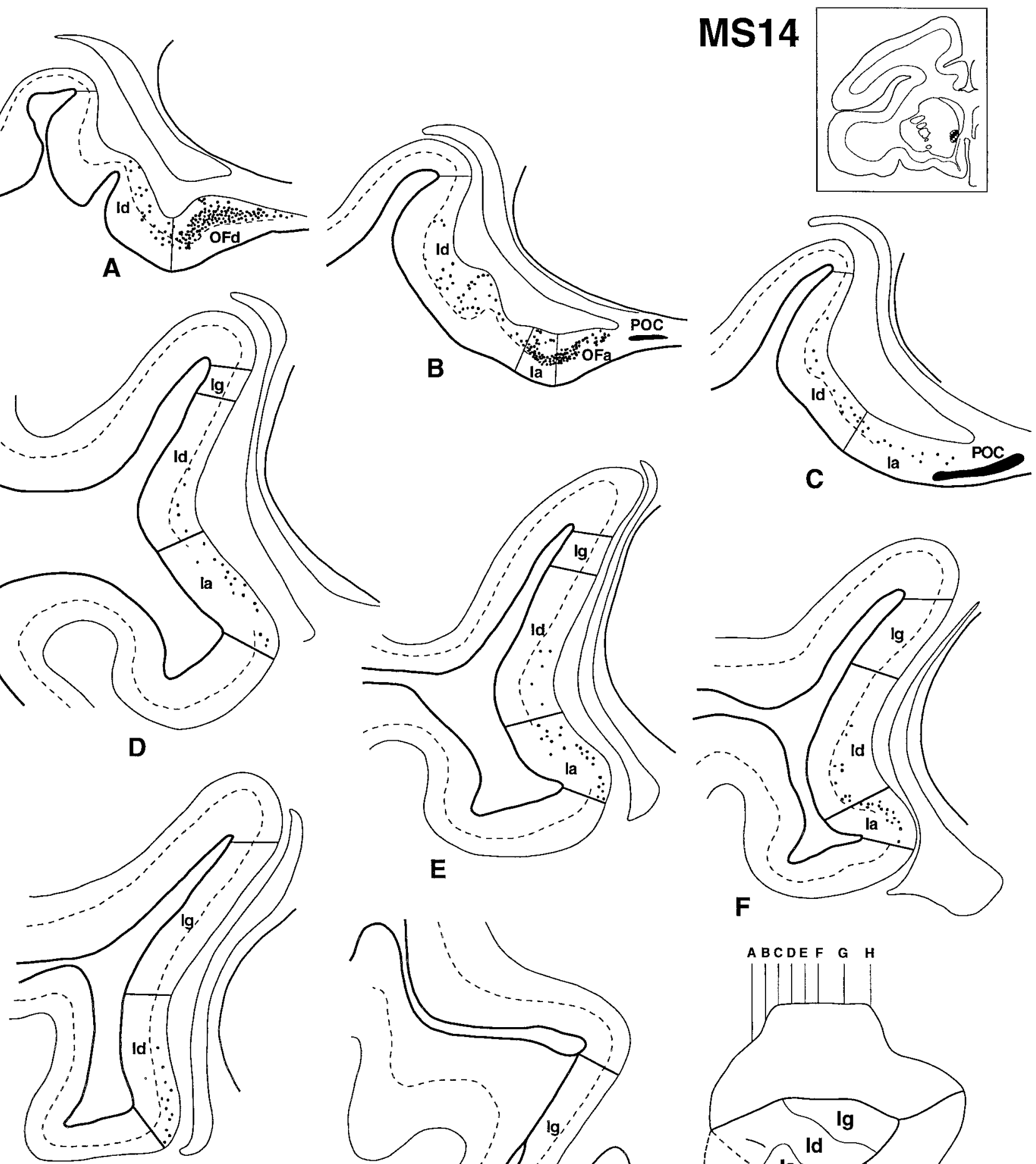

G
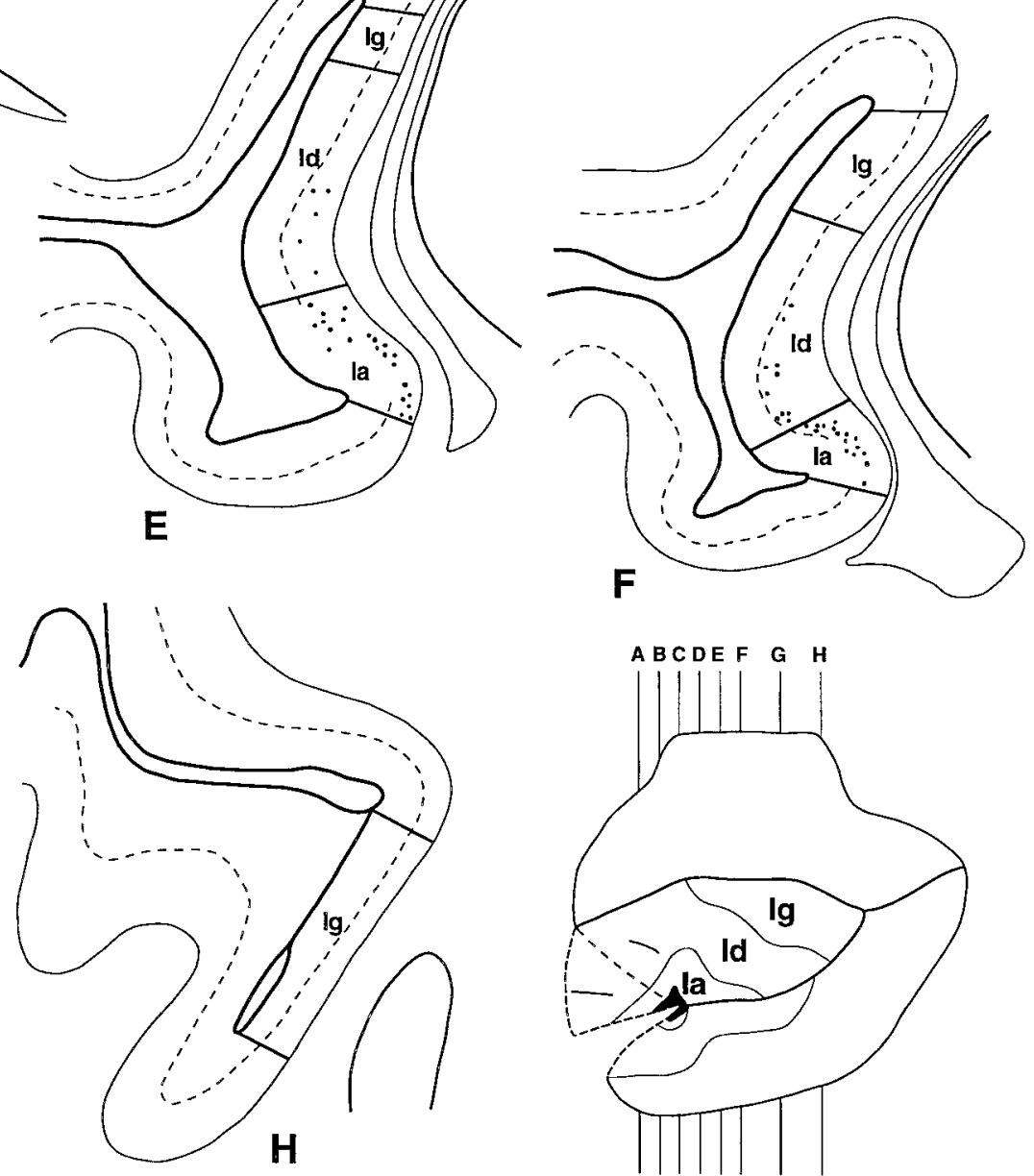

Figure 5. Schematic chartings of the distribution of the retrogradely labeled cells in the insula after injection of WGA-HRP into the medial ventral striatum (case MS14). $A-F$, Serial coronal sections through the insula (rostral-caudal), each $1.2 \mathrm{~mm}$ apart. $F-H$, Sections are each $2.4 \mathrm{~mm}$ apart. Dashed lines represent the boundary between layers IV and V. Each dot represents one labeled cell. $O F a$, Agranular orbitofrontal cortex; $O F d$, dysgranular orbitofrontal cortex; $P O C$, piriform olfactory cortex. 


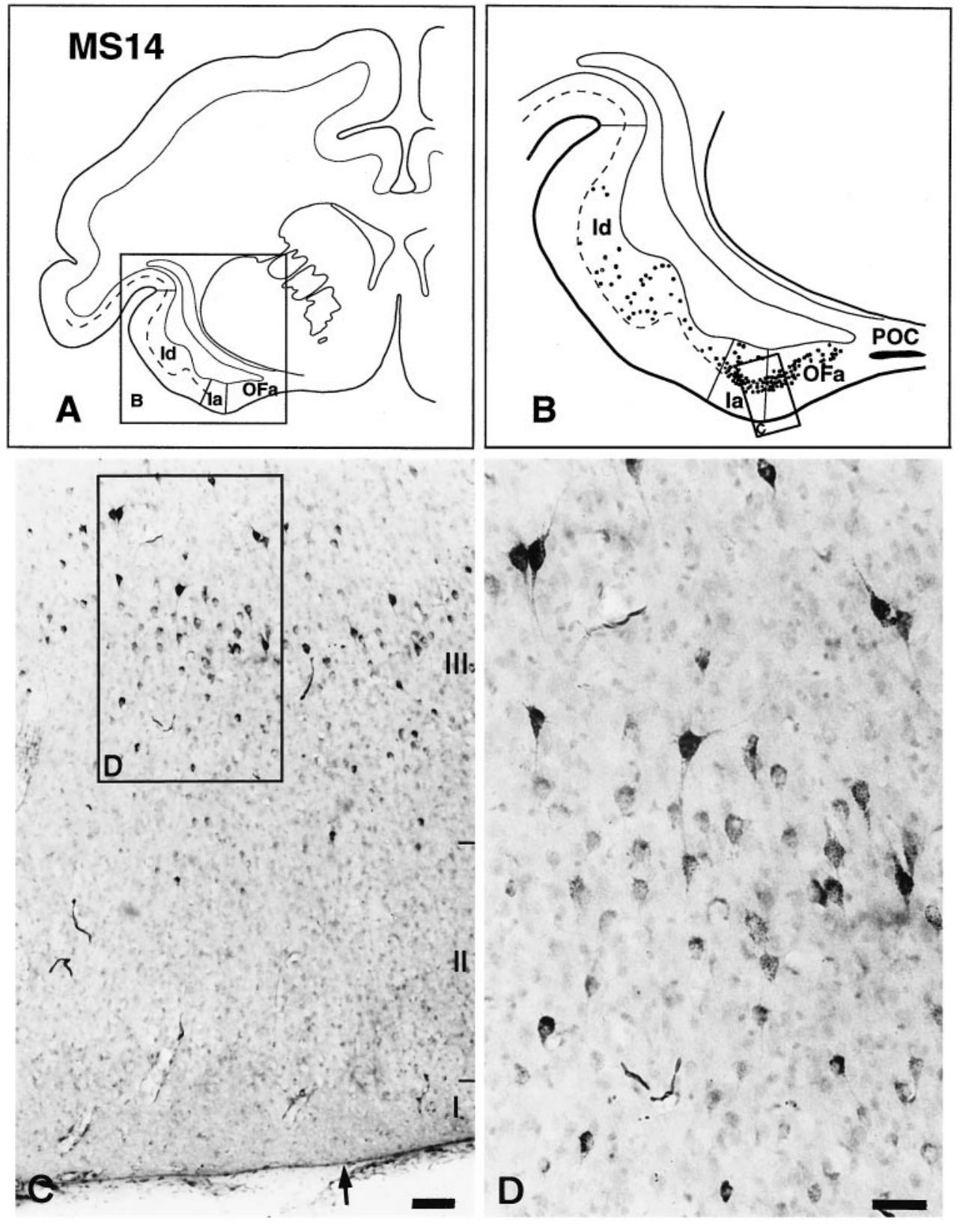

Figure 6. Photomicrographs taken from rostral level of the insular cortex in case MS14 (Fig. 5B). A, Schematic illustration of the rostral portion of the insular cortex and the adjacent caudal portion of the orbitofrontal cortex. Black rectangle marked $B$ in $6 A$ is shown in $6 B . B$, Schematic illustration of retrogradely labeled neurons in Ia, the ventral portion of Id and OFa. Black rectangle marked $C$ in $6 B$ is demonstrated in $6 C$. $C$, Labeled cells are found primarily in the inner stratum of Ia. Scale bar, $100 \mu \mathrm{m}$. Layers I, II (the outer pyramidal layer), and III (the inner pyramidal layer) are indicated. $D$, High-magnification photomicrograph of box in $6 C$. Many cells are densely labeled, and others are lightly stained. Scale bar, $50 \mu \mathrm{m}$. relatively low. Only scattered silver grains are found in the lateral ventral striatum. At the central level (Fig. 12F, G), the dense patches of labeling occupy the ventral portion of the putamen and the ventral portion of the caudate nucleus, including the central ventral striatum. Little labeling is found in the ventromedial edge of the striatum. Caudally, the labeling extends into the ventral portion of the body of the caudate nucleus and into the medial and ventral portion of the caudal putamen (Fig. 12H,I). No labeling is observed in the dorsal caudate nucleus, tail, or dorsolateral putamen.

\section{Dysgranular insular cortical projections (case M8-93)}

In contrast to that in case M1-89, the distribution of silver grain deposits is more limited in case M8-93 (Fig. 13). However, patches of labeling in case M8-93 are often found in striatal regions that contain label in case M1-89. Labeling in the head of the caudate nucleus begins more caudally than that in case M1-89 and is restricted to small patches along the medial border of the internal capsule that extends caudally into the lateral and ventral portion of the body of the caudate nucleus. The densest silver grain deposits are found in the ventral putamen, including the central ventral striatum at the level of the shell. Silver grain deposits do not extend into the shell. Similar to that in case M1-89, labeling extends caudally along the medial, ventral border of the putamen (Fig. $13 A-D)$. At central levels, a patch of terminals is seen at the ventral junction of the putamen with the tail of the caudate nucleus (Fig. 13E,F). Caudally, few scattered silver grains are found in the medioventral portion of the putamen and in the ventral portion of the caudate nucleus (Fig. 13G,H). Labeling in this case extends more caudally in the putamen than in case M1-89. In contrast to that in case M1-89, there are small, dense patches of silver grains in the dorsolateral, postcommissural putamen (compare Figs. 12I, 13E,F). There are no silver grains in the dorsal head and tail of the caudate nucleus. 

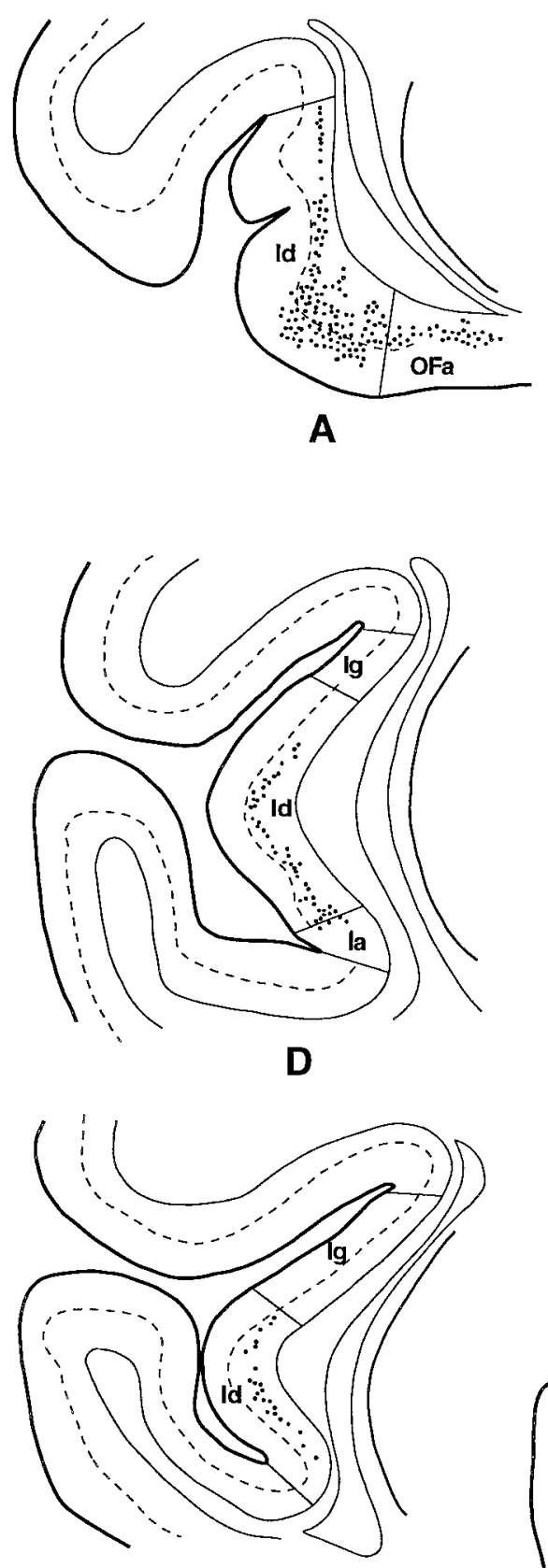

G
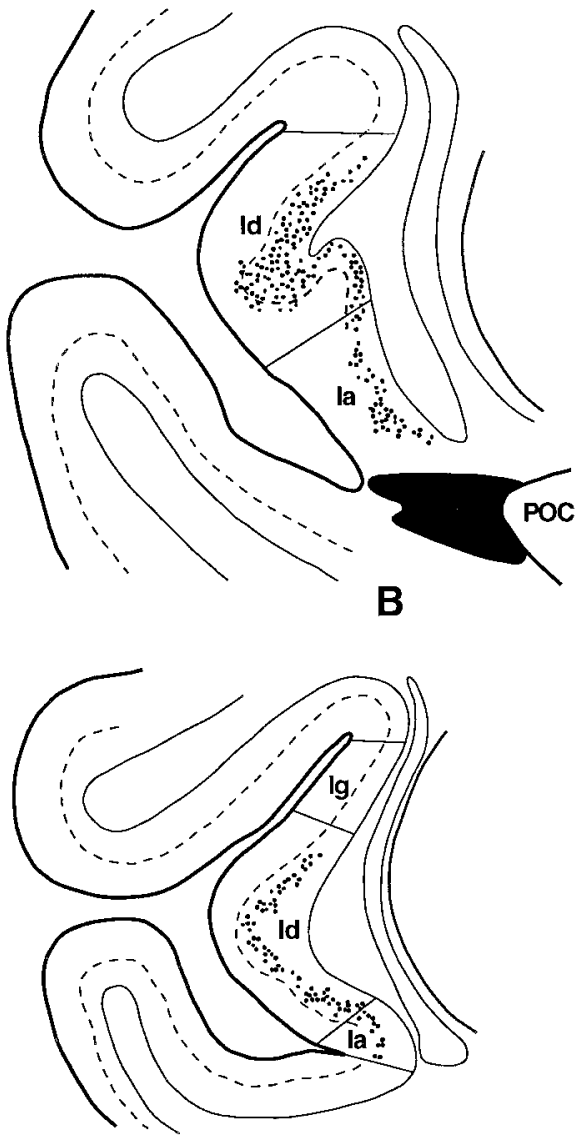

E

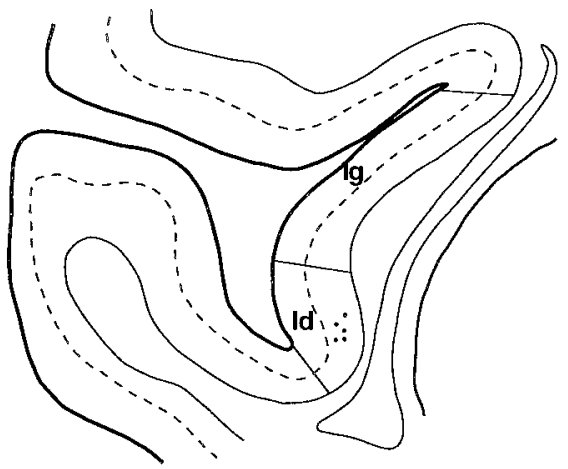

H
MS49
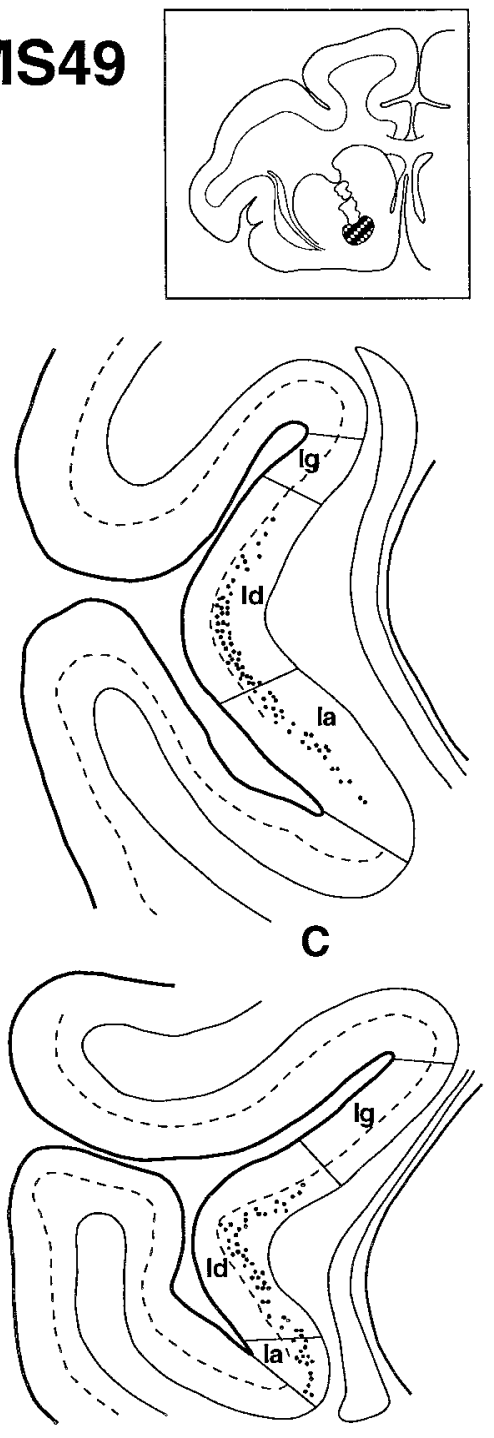

$\mathbf{F}$

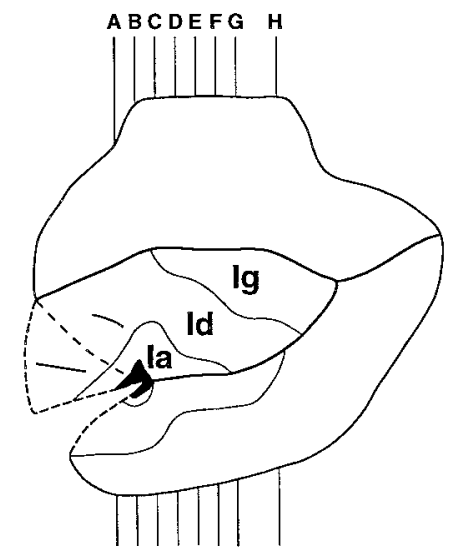

Figure 7. Schematic chartings of the distribution of the retrogradely labeled cells in the insula after injection of LY into the central ventral striatum (case MS49). $A-G$, Serial coronal sections through the insula (rostral-caudal), each $1.2 \mathrm{~mm}$ apart. Sections $G$ and $H$ are $2.4 \mathrm{~mm}$ apart. Dashed lines represent the boundary between layers IV and V. Each dot represents one labeled cell. OFa, Agranular orbitofrontal cortex; $P O C$, piriform olfactory cortex. 


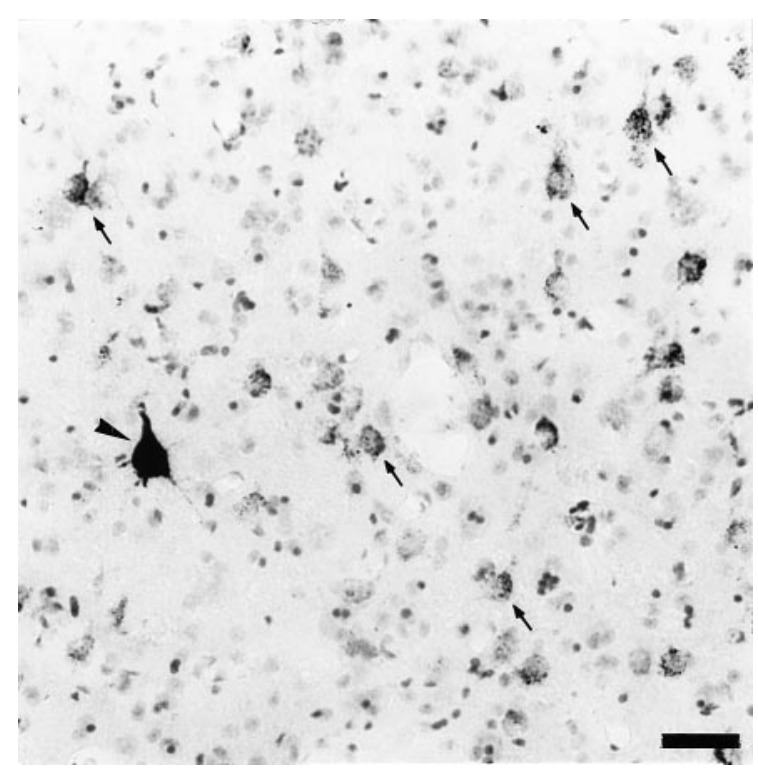

Figure 8. Photomicrograph taken from the rostral level of Id in case MS49 (Fig. 7B). A number of labeled cells are found primarily in layer V of Id. Although some cells are densely labeled (arrowhead), most are lightly stained (small arrows) with punctate, cytoplasmic granules. Scale bar, $50 \mu \mathrm{m}$.

\section{Granular insular cortical projections (case M9-94)}

Silver grains are distributed widely throughout the striatum, including large areas of the dorsal caudate nucleus and dorsolateral putamen (Fig. 14). In contrast to both dysgranular and agranular insulostriatal projections, granular insular terminals generally are not found in the ventral striatum (Fig. 14C-E). The densest labeling is observed in the central portion of the rostral putamen (Fig. 14D,E). Less dense patches of label are found in the lateral portion of the head of the caudate nucleus, beginning at the level of the anterior commissure and extending caudally into the ventral portion of the body of the caudate nucleus. Silver grain patches are also scattered throughout the rostral-caudal extent of the putamen (Fig. $14 F-K$ ). Unlike that in cases M1-89 and M8-93, no significant labeling is found along the medial border of the postcommissural putamen. However, similar to that in cases M1-89 and M8-93, a dense patch of silver grains is located at the junction of the ventral putamen with the rostral tail of the caudate.

\section{DISCUSSION}

\section{Summary of the retrograde and anterograde studies}

The cytoarchitectonic regions of the insula project onto the striatum creating a continuum of inputs onto the different functional territories. The retrograde studies show that the shell and the medial ventral striatum receive inputs primarily from the rostral portion of Ia and from the adjacent ventral Id (Fig. $15 A, B)$. The central ventral striatum receives inputs from both Ia and Id (Fig. 15C). However, compared with insular projections to the medial ventral striatum, insular neurons projecting to the central ventral striatum are distributed more posterior and dorsal. The lateral ventral striatum receives few inputs from Id (Fig. $15 D)$. In contrast to the ventral striatum, the dorsolateral striatum receives inputs primarily from dorsal and posterior parts of the insula, which are granular (Fig. 15E, F). The anterograde tracer experiments generally confirm these results. The central portion of the Ia, including the adjacent ventral Id (case M1-89), projects onto a wide area of the anteroventral striatum and extends caudally into the body of the caudate and medioventral putamen. Id terminals (case M8-93) have a more limited distribution that overlaps that from the Ia, but are most prominent in the central ventral striatum. Terminals from the Id, however, do not extend into the shell or medial ventral striatum. Projections from case M1-89 to the central caudate nucleus may be explained in part by the size of the injection in case M1-89, which extends into the adjacent Id. The fact that an injection into the Id did not result in labeling in the shell or medial ventral striatum suggests that the Ia is the primary source of insular input to these striatal regions. In contrast to the Ia and Id, the dorsal portion of Ig terminates primarily in the central portion of the dorsal putamen (case M9-94). The findings presented above thus demonstrate graded projections from the cytoarchitectonic regions of the insula onto the striatum, such that the Ia projects primarily to the rostral, medioventral striatum, the Id projects to the central ventral striatum, and the Ig projects primarily to the dorsal striatum (Figs. $15 A-F, 16 A)$.

\section{Different cytoarchitectonic areas of insular, cingulate, and OMPFCs project topographically to different functional domains of the striatum}

Based on the distribution of corticostriatal projections, the striatum generally is divided into different functional domains, such that the ventral striatum is primarily "limbic" in function, whereas the dorsolateral striatum is concerned primarily with "sensorimotor" functions (Künzle, 1975; Jones et al., 1977; Hemphill et al., 1981; Selemon and Goldman-Rakic, 1985; Yeterian and Pandya, 1991; Yeterian and Pandya, 1993; Haber et al., 1994). The organization of projections to these different functional domains from the cortex is related to the cortical cytoarchitectonic differentiation. The rostral part of the anterior cingulate cortex (areas 24a and ventral 24b), medial prefrontal cortex (areas 25 and 32), posterior part of the orbital cortex (area 13a), and temporal polar region, which are linked closely to the amygdala and hippocampus (Herzog and Van Hoesen, 1976; Aggleton et al., 1980; Baleydier and Mauguiere, 1980; Amaral and Price, 1984; Carmichael and Price, 1996), all project to the ventral striatum, particularly the shell and medial ventral striatum (Fig. 16B) (Hemphill et al., 1981; Van Hoesen et al., 1981; Kunishio and Haber, 1994; Haber et al., 1995). Cytoarchitectonic features of these cortical areas are less differentiated in that they are primarily agranular (Vogt et al., 1987; Barbas and Pandya, 1989; Morecraft et al., 1992; Carmichael and Price, 1994). The agranular insula, including the adjacent caudal orbitofrontal cortex and the ventral Id, project primarily to the shell and the medial ventral striatum (Fig. 16A). Furthermore, this insular region also has reciprocal connections with the amygdala and the entorhinal cortex (Aggleton et al., 1980; Mufson and Mesulam, 1982; Amaral and Price, 1984; Insausti et al., 1987; Carmichael and Price, 1996). In contrast, as with prefrontal association cortices, the central and lateral parts of the orbital cortex (areas 11-13) and parts of the cingulate cortex (areas 23b and dorsal 24b and lower bank of area $24 \mathrm{c}$ ), which are adjacent to agranular areas, have connections with both multimodal sensory and agranular areas (Barbas and Pandya, 1989; Barbas, 1992; Morecraft et al., 1992; Van Hoesen et al., 1993). These cortical areas possess cytoarchitectonic features intermediate to agranular and granular areas and project primarily to the central and lateral ventral striatum (Fig. 16B) (Kunishio and Haber, 1994; Haber et al., 1995). Similarly, Id has connections 


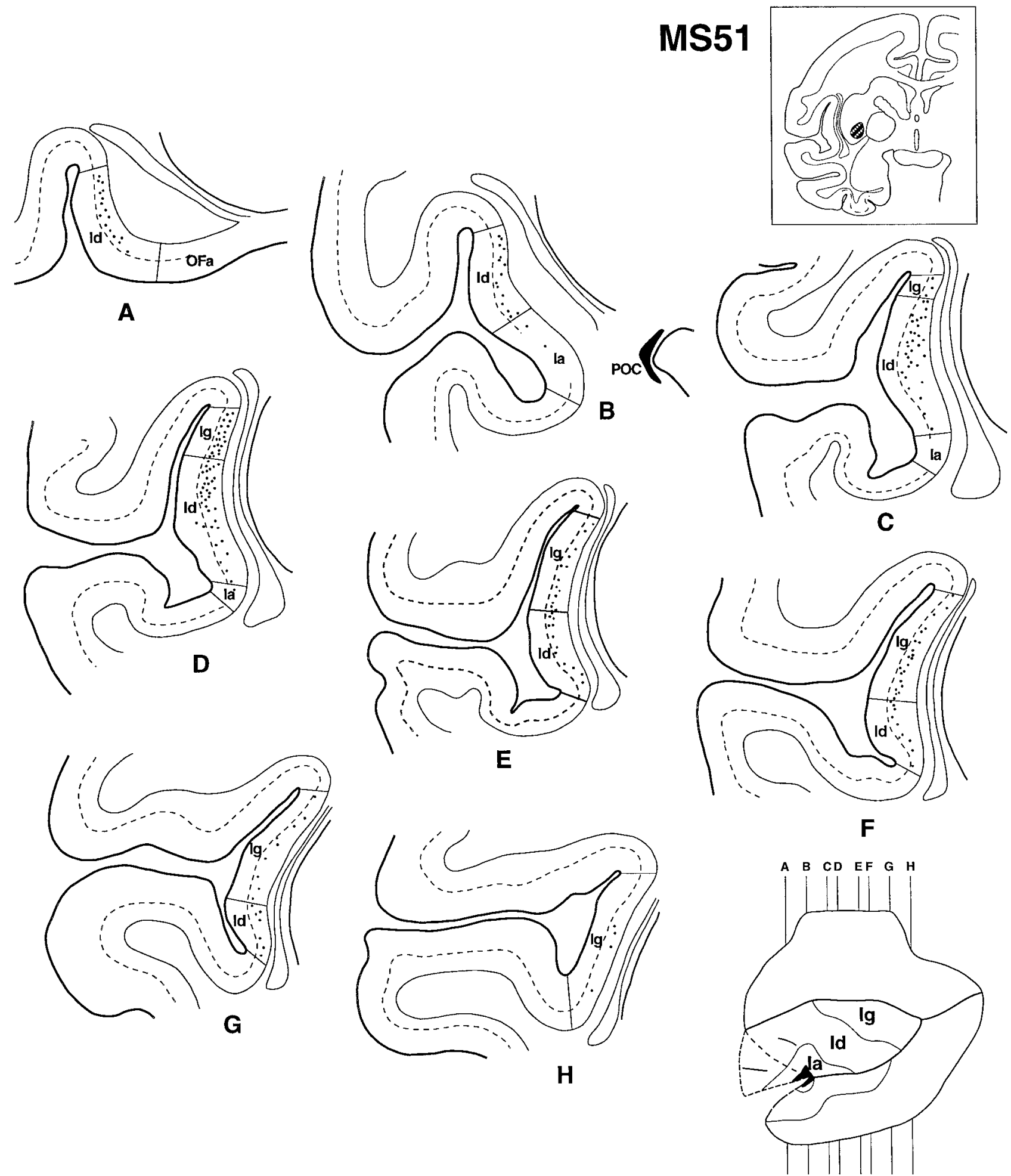

Figure 9. Schematic chartings of the distribution of the retrogradely cells in the insula after injection of WGA-HRP into the caudal and ventral portion of the dorsolateral striatum (case MS51). $A-H$, Serial coronal sections through the insula (rostral-caudal). All sections are $2.4 \mathrm{~mm}$ apart except $C$ and $D$ and $E$ and $F$, which are $1.2 \mathrm{~mm}$ apart. Dashed lines represent the boundary between layers IV and V. Each dot represents one labeled cell. $O F a$, Agranular orbitofrontal cortex; $P O C$, piriform olfactory cortex.

with both multimodal and agranular areas (Mufson and Mesulam, 1982; Mesulam and Mufson, 1982b) and projects primarily to the central and lateral ventral striatum (Fig. 16A).

Dorsal and posterior parts of the cingulate cortex (fundus of area $24 \mathrm{c}$ and $23 \mathrm{c}$ and area 31 ) project to the dorsolateral striatum, which also receives sensorimotor cortical inputs. The fundus area of the cingulate sulcus is considered the most cytoarchitectonically differentiated region of the cingulate cortex, possessing 


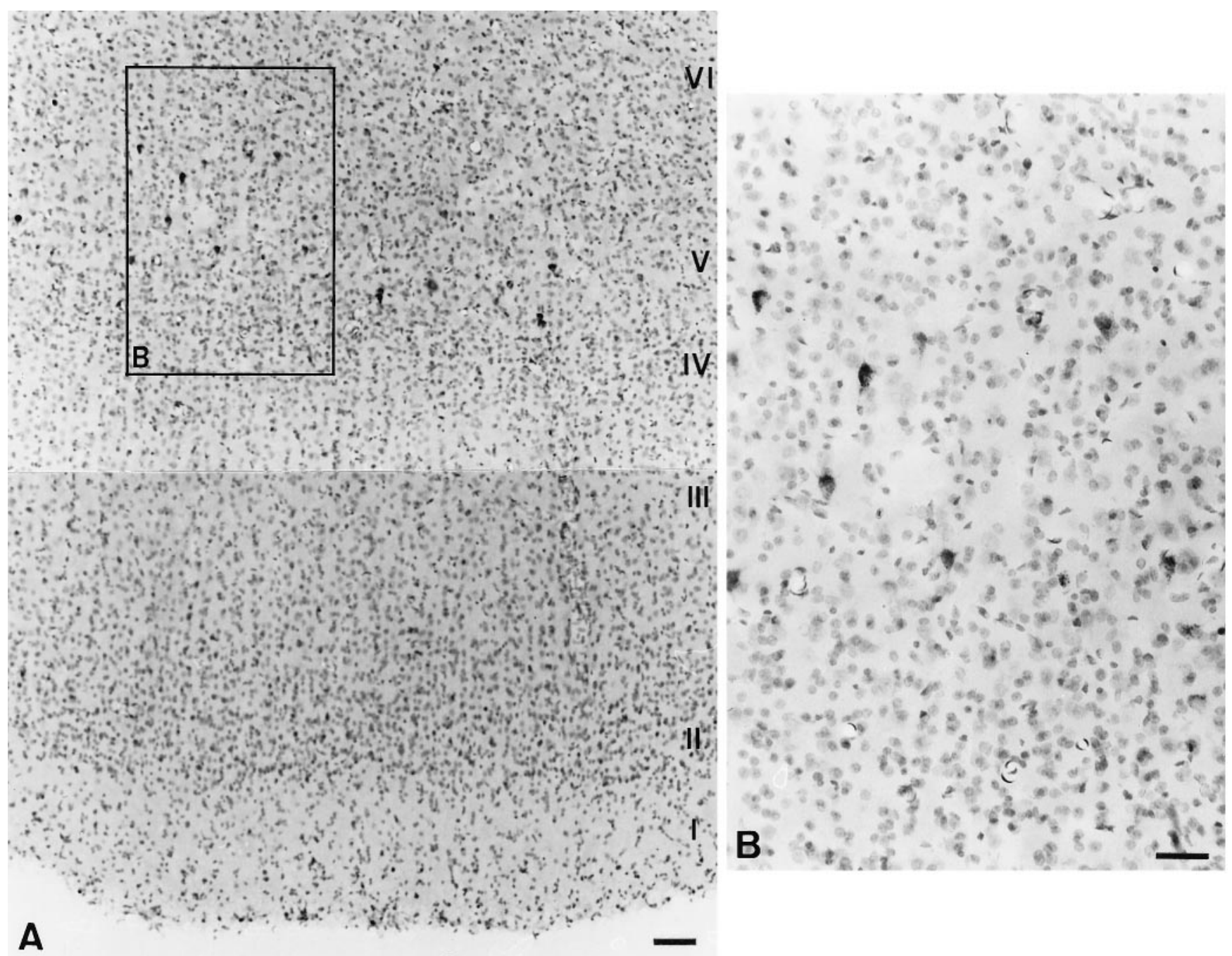

Figure 10. Photomicrographs taken from the central level of the insular cortex in case MS51 (Fig. 9E). $A$, WGA-HRP-positive neurons are found primarily in layers V and VI of both Id and Ig. Scale bar, $100 \mu \mathrm{m}$. B. High-magnification photomicrograph of area inside box in $10 A$. Scattered cells are densely labeled. Scale bar, $50 \mu \mathrm{m}$.

well-defined layers V and VI and a granular layer IV (Vogt et al., 1987; Suddath et al., 1990). This cingulate region (including areas $24 \mathrm{c}$ and $23 \mathrm{c}$ ) has connections with primary motor and supplementary motor cortices (Morecraft and Van Hoesen, 1992). Area 23c also receives projections from the parietal cortex (Van Hoesen et al., 1993). The granular insula and the dorsal portion of Id also have reciprocal connections with sensorimotor cortices (Mufson and Mesulam, 1982; Mesulam and Mufson, 1982b), particularly with the secondary somatosensory area $\left(\mathrm{S}_{2}\right)$ (Friedman et al., 1986; Schneider et al., 1993). Thus, highly differentiated regions of the cingulate and insular cortices project primarily to the dorsolateral "sensorimotor" striatum. In summary, the different cytoarchitectonic regions of the cortex are associated with different functions and project to similar functional regions of the striatum (Fig. 16B).

\section{Functional considerations}

Function of agranular and ventral dysgranular insulostriatal projections

The cytoarchitectonic differentiation of the insula is associated closely with its different functions (Mesulam and Mufson, 1993).
The POC projects to Ia, the anterior Id, and the caudal orbitofrontal cortex (Mufson and Mesulam, 1982; Carmichael et al., 1994). Olfactory sensation and several autonomic responses, including salivatory and gastrointestinal modalities, can be elicited by stimulating the anterior insula (Kaada et al., 1949; Hoffman and Rasmussen, 1953; Penfield and Faulk, 1955; Showers and Lauer, 1961). In humans, changes in gastrointestinal motility and the emergence of variable sensations in the digestive tract are also observed with stimulation of the anterior insula. These studies suggest that Ia and the ventral portion of Id contribute to olfactory and autonomic functions associated with feeding behavior. The caudal orbitofrontal region, including the anterior insula, has also been proposed to relate "reward" and mnemonic processes to feeding behavior, based on its reciprocal connections with the amygdala and hippocampus via the entorhinal cortex (Carmichael and Price, 1996). Ablations of the posterior orbital cortex, including the adjacent Ia, cause impairment of extinction to bar press for food reward (Butter, 1969). Moreover, there is evidence that glutamatergic input to the nucleus accumbens shell may modulate feeding behavior (Moldonado-Irizarry et al., 1995). Taken to- 


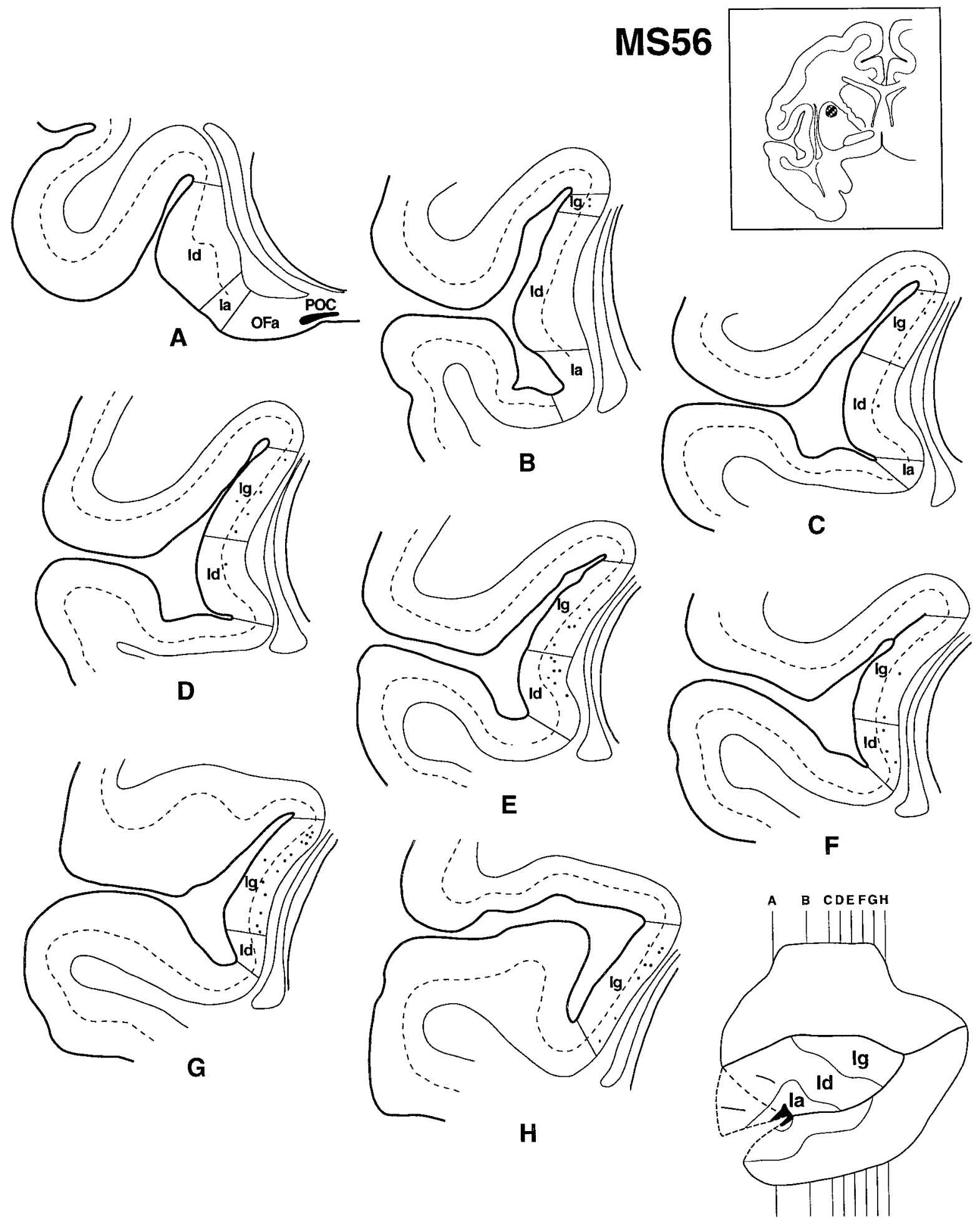

Figure 11. Schematic chartings of the distribution of the retrogradely cells in the insula after injection of LY into the rostral and dorsal portion of the dorsolateral striatum (case MS56). $A-H$, Serial coronal sections through the insula (rostral-caudal). All sections are $1.2 \mathrm{~mm}$ apart except $A$ and $B$ (3.6 $\mathrm{mm})$ and $B$ and $C(2.4 \mathrm{~mm})$. Dashed lines represent the boundary between layers IV and V. Each dot represents one labeled cell. OFa, Agranular orbitofrontal cortex; $P O C$, piriform olfactory cortex.

gether, these data suggest that projections from Ia, including the adjacent caudal orbitofrontal region, and ventral Id to the ventromedial limbic portion of the ventral striatum may integrate feeding behavior with rewards and memory.
Function of granular and dorsal dysgranular insulostriatal projections

Based on physiological studies, the posterior insula is thought primarily to process somatosensory information (Hoffman and 

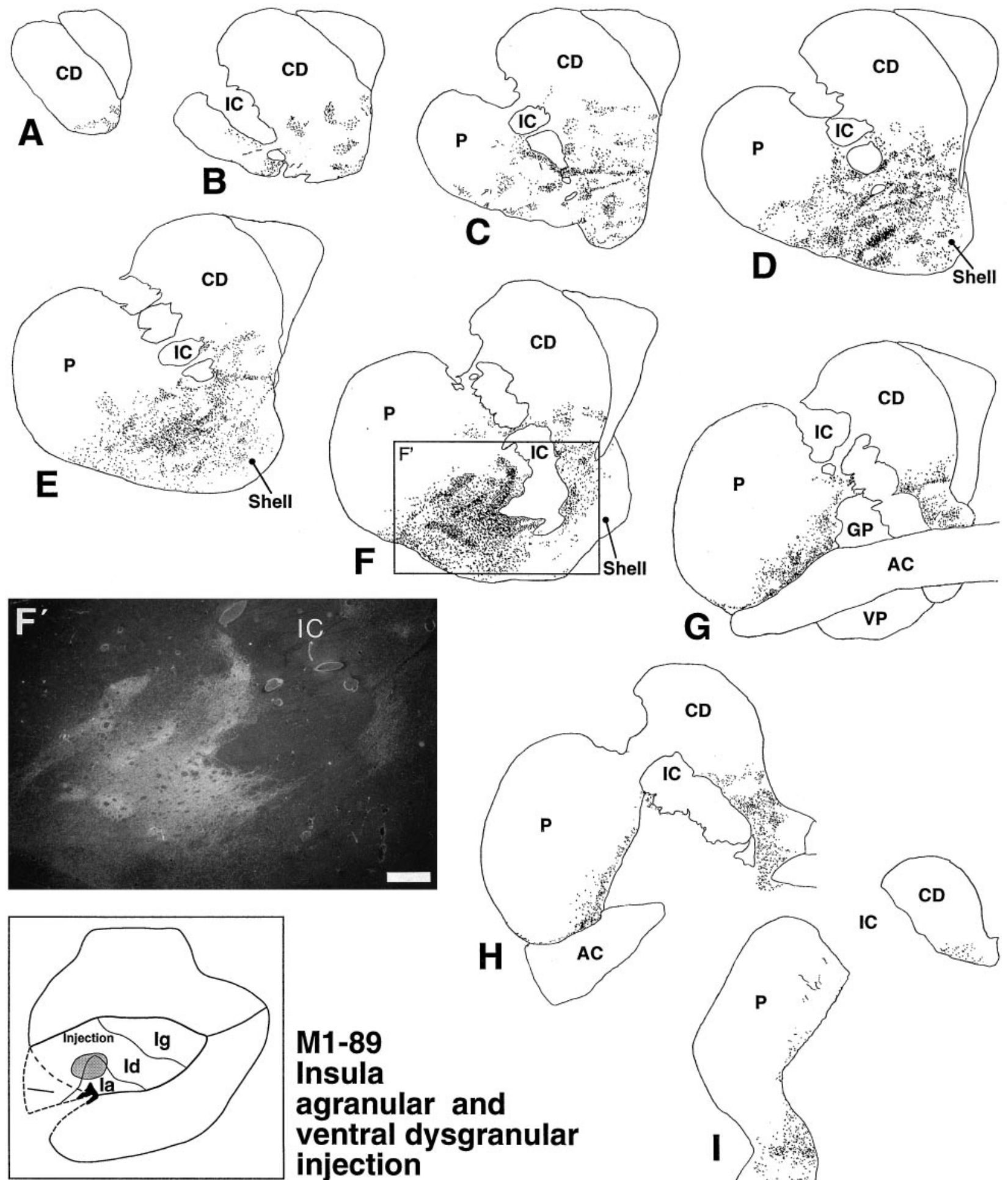

M1-89

\section{Insula}

\section{agranular and} ventral dysgranular injection

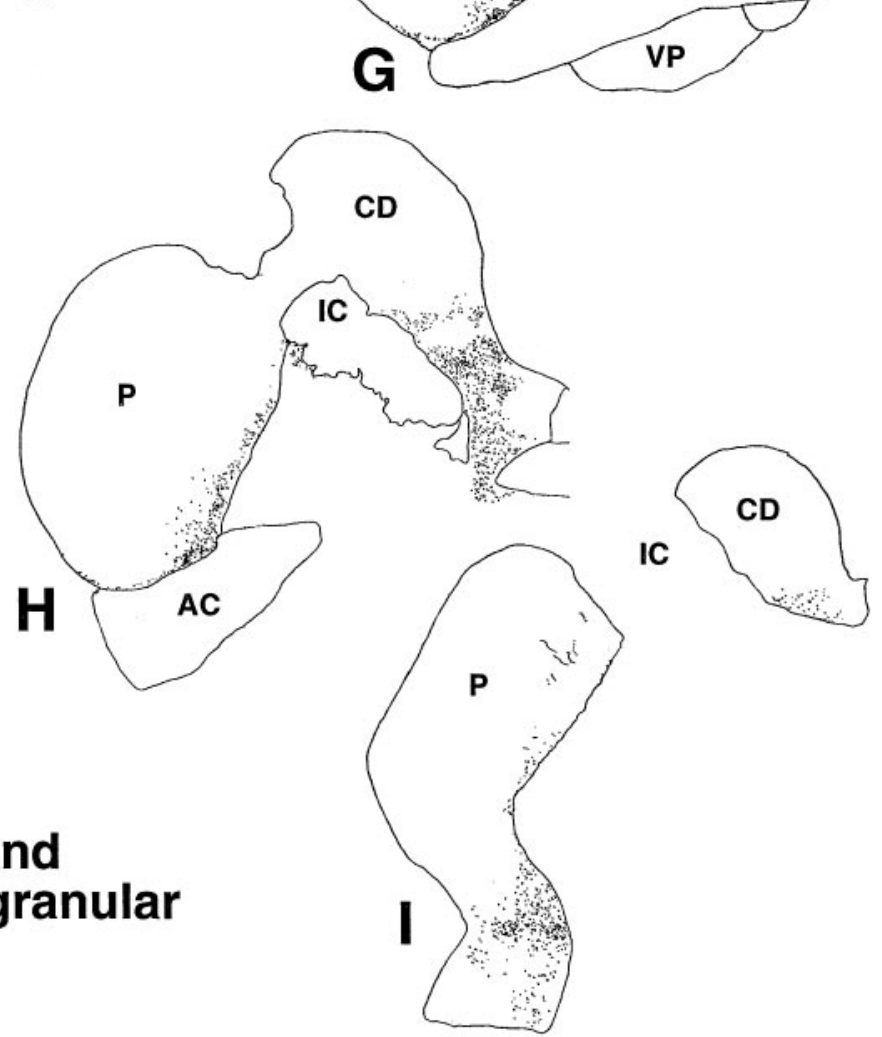

Figure 12. A-I, Rostral-caudal drawings of the distribution of anterograde labeled terminals in the striatum after a tritiated amino acid injection into the central portion of the agranular insula and the adjacent dysgranular insula (case M1-89). The distance between each section is $1.2 \mathrm{~mm}(H$ and $I$ are $2.4 \mathrm{~mm}$ apart). $F^{\prime}$, Photomicrograph showing detail of area boxed in $F$. White areas represent silver grains over labeled terminals. Scale bar, $1 \mathrm{~mm}$. $C D$, Caudate nucleus; $P$, putamen; $V P$, ventral putamen; $G P$, globus pallidum; $A C$, anterior commissure; $I C$, internal capsule.

Rasmussen, 1953; Schneider et al., 1993). Several clinicopathological studies also suggest that the posterior insula is involved in pain and temperature sensation (Berthier et al., 1988; Greenspan and Winfield, 1992; Casey et al., 1994). Somatosensory input to Id and Ig arises primarily from the secondary somatosensory area $\left(\mathrm{S}_{2}\right)$ (Mufson and Mesulam, 1982; Friedman et al., 1986). In particular, the anterior Ig and adjacent Id receive inputs primarily from hand and face regions of $\mathrm{S}_{2}$, whereas the posterior Ig 


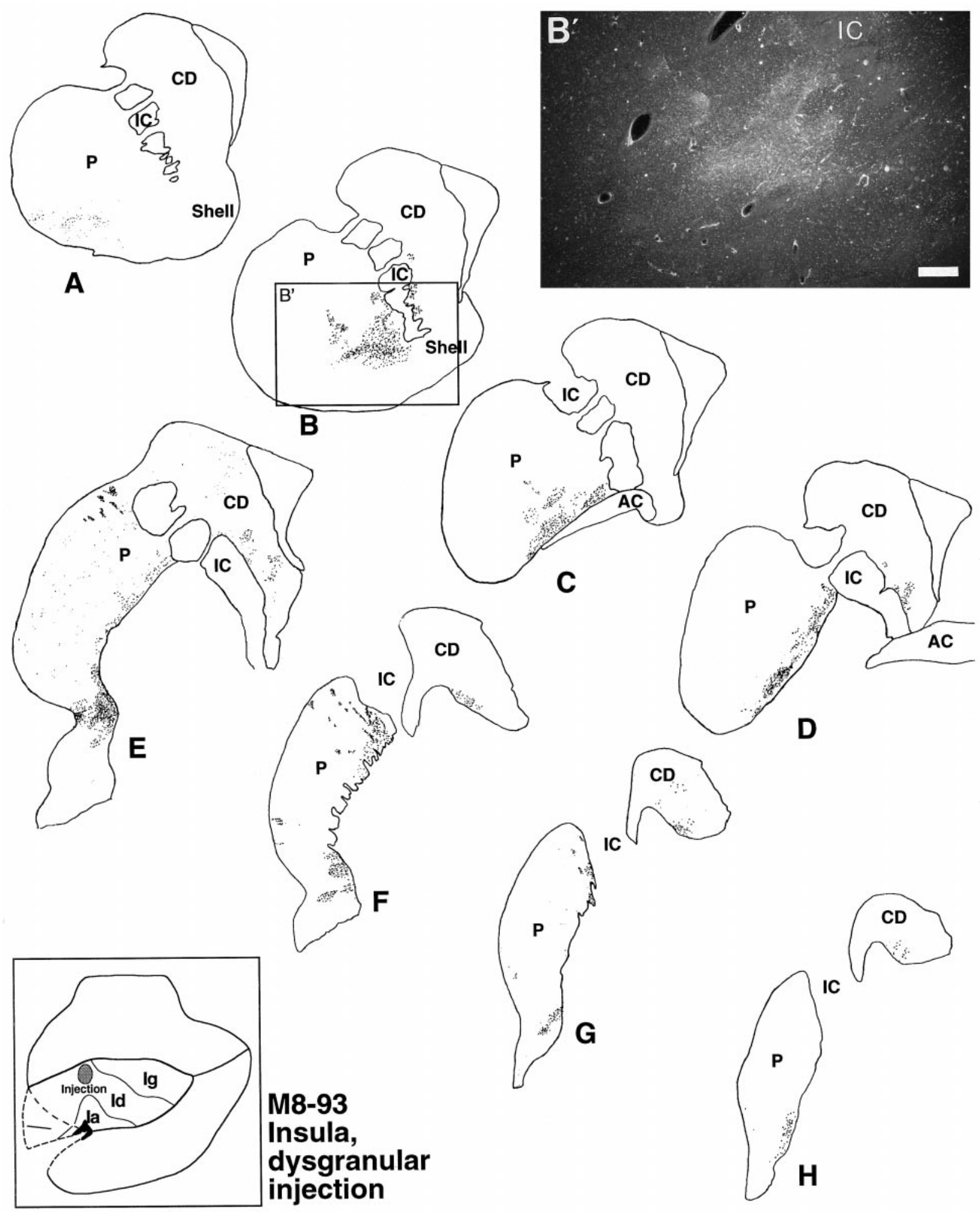

Figure 13. $A-H$, Rostral-caudal drawings of the distribution of anterograde labeled terminals in the striatum after a tritiated amino acid injection into the dysgranular insula (case M8-93). The distance between each section is $1.2 \mathrm{~mm}$. $B^{\prime}$, Photomicrograph showing detail of area boxed in 13B. White areas represent silver grains over labeled terminals. Scale bar, $1 \mathrm{~mm}$. $C D$, Caudate nucleus; $P$, putamen; $A C$, anterior commissure; $I C$, internal capsule.

receives inputs primarily from leg and arm regions of $\mathrm{S}_{2}$. Physiological studies support these anatomical findings in that the anterior Ig responds to cutaneous stimulation of the intraoral or facial region of the somatosensory cortex, and the posterior Ig responds to cutaneous stimulation of the torso and leg (Robinson and Burton, 1980; Schneider et al., 1993). In the present study, the anterior Ig and adjacent Id projects predominantly to the ventral portion of the dorsolateral striatum (case MS51), whereas the 


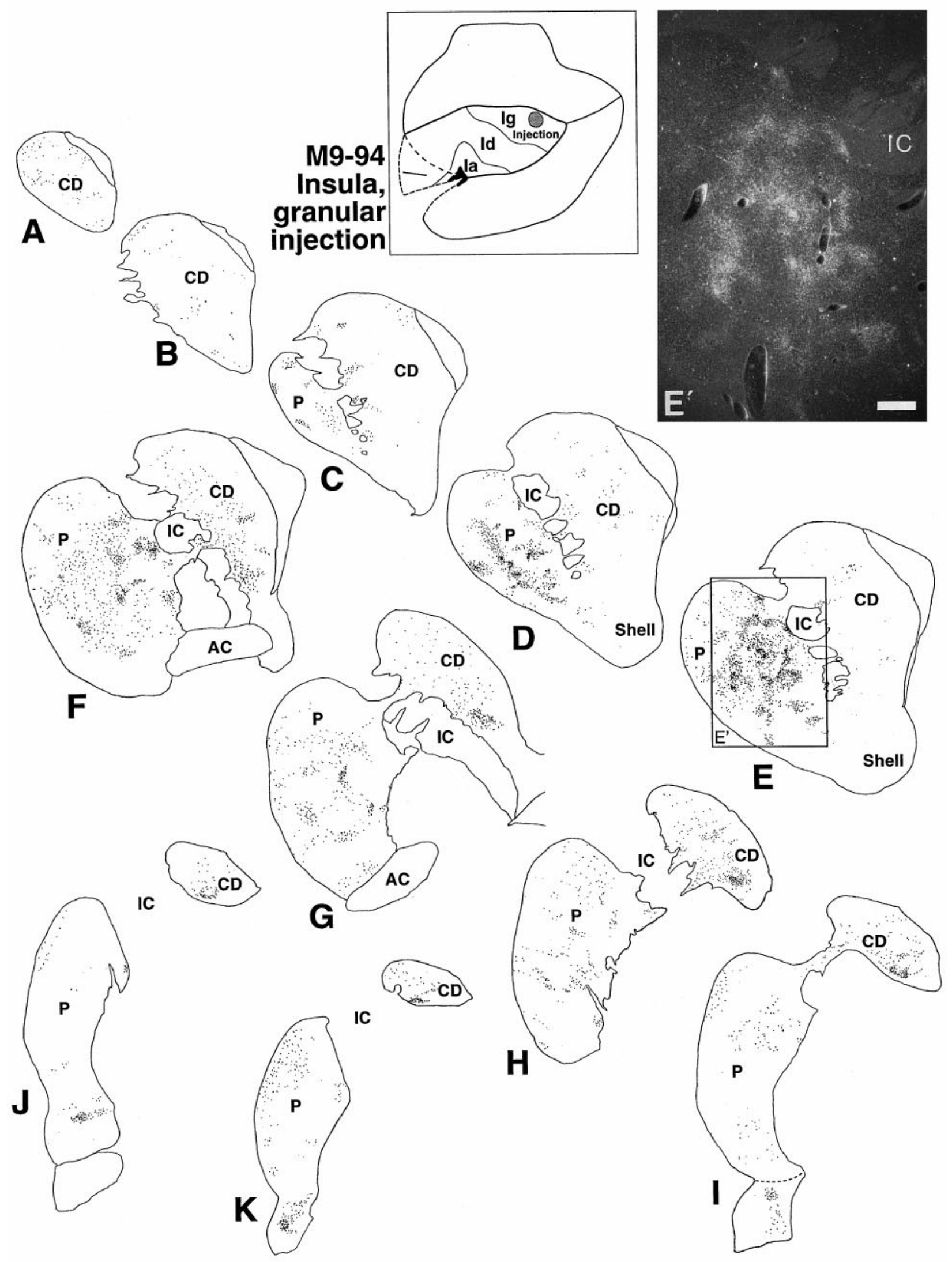

Figure 14. A-K, Rostral-caudal drawings of the distribution of anterograde labeled terminals in the striatum after a tritiated amino acid injection into the granular insula (case M9-94). The distance between each section is $1.2 \mathrm{~mm}$. E', Photomicrograph showing detail of area boxed in $14 E$. White areas represent silver grains over labeled terminals. Scale bar, $1 \mathrm{~mm}$. $C D$, Caudate nucleus; $P$, putamen; $A C$, anterior commissure; $I C$, internal capsule. 

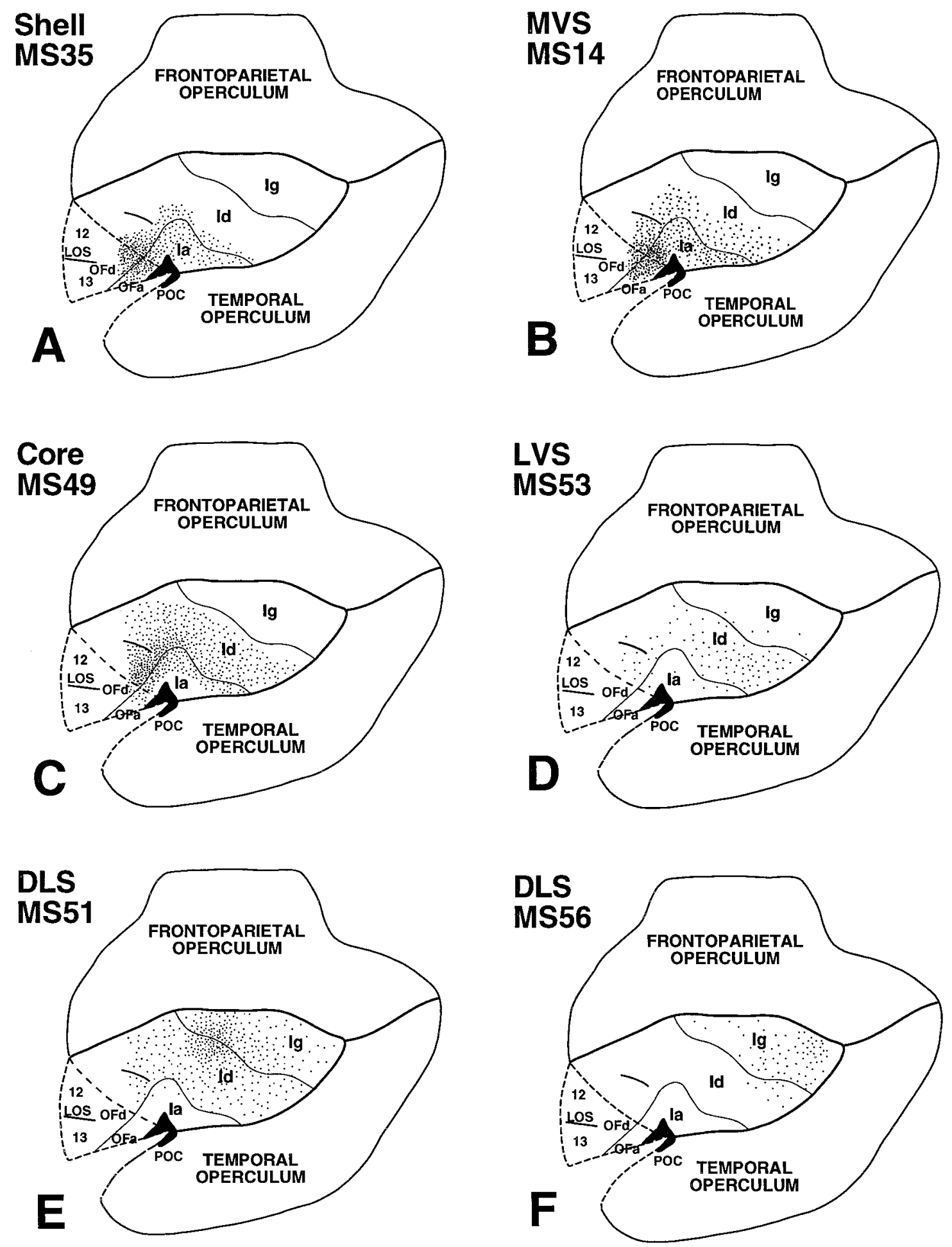

Figure 15. Summary illustrations of the distributions of labeled cells after injections of retrograde tracers into six different regions of the striatum. Labeled cells were plotted on the schematic diagram of the insula (after opening the Sylvian fissure) (diagram modified from Mesulam and Mufson, $1982 b$ ) by visually approximating the dorsal-ventral location of each labeled cell in serial coronal sections through the insula. $A$, Injection into the shell of the nucleus accumbens (case MS35). $B$, Injection into the medial ventral striatum (case MS14). $C$, Injection of the central ventral striatum (case MS49). $D$, Injection into the lateral the ventral striatum (case MS53). E, Injection into the caudal and ventral portion of the dorsolateral striatum (case MS51). $F$, Injection into the rostral and dorsal portion of the dorsolateral striatum (case MS56). Each dot represents one labeled cell. OFa, Agranular orbitofrontal cortex; $O F d$, dysgranular orbitofrontal cortex; $P O C$, piriform olfactory cortex; $L O S$, lateral orbitofrontal sulcus. 

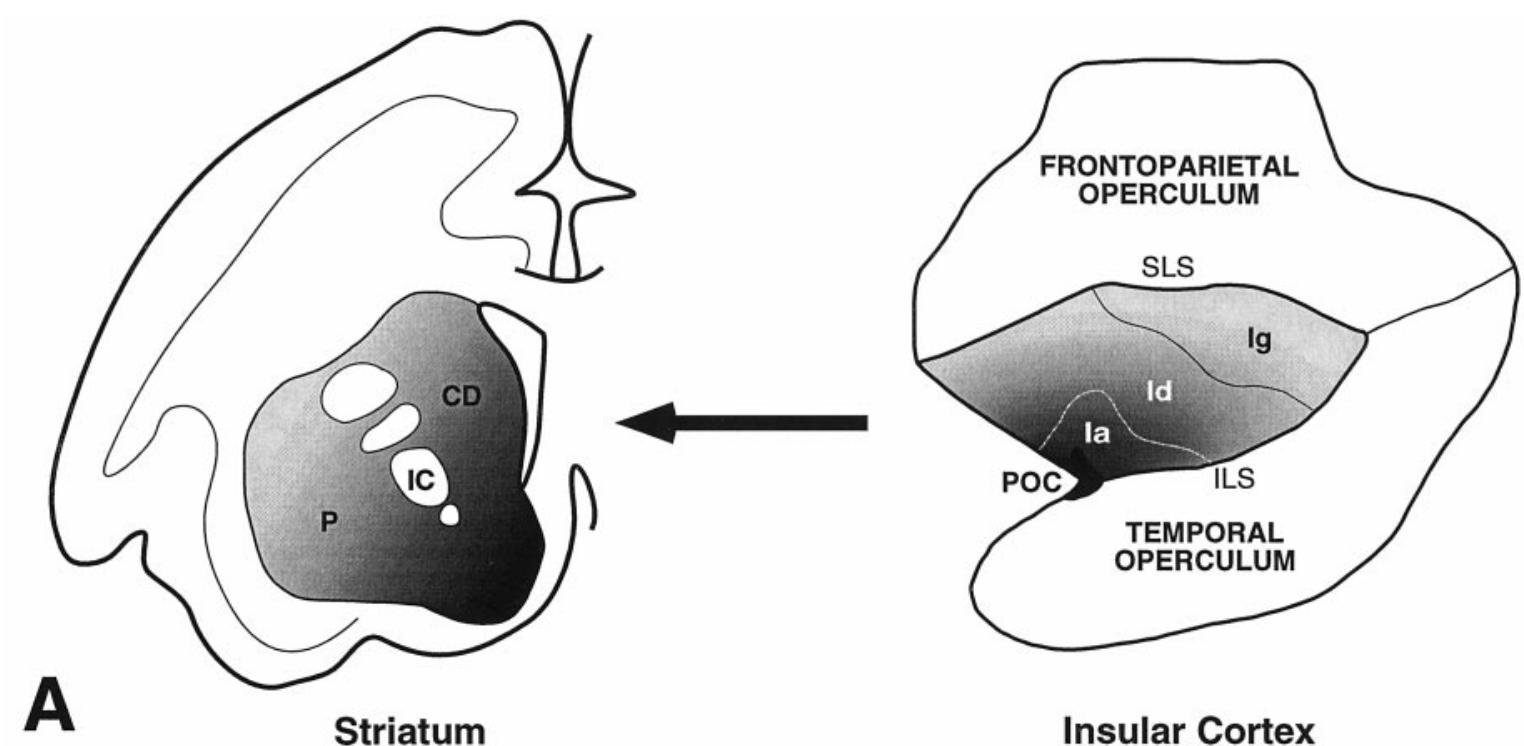

Insular Cortex

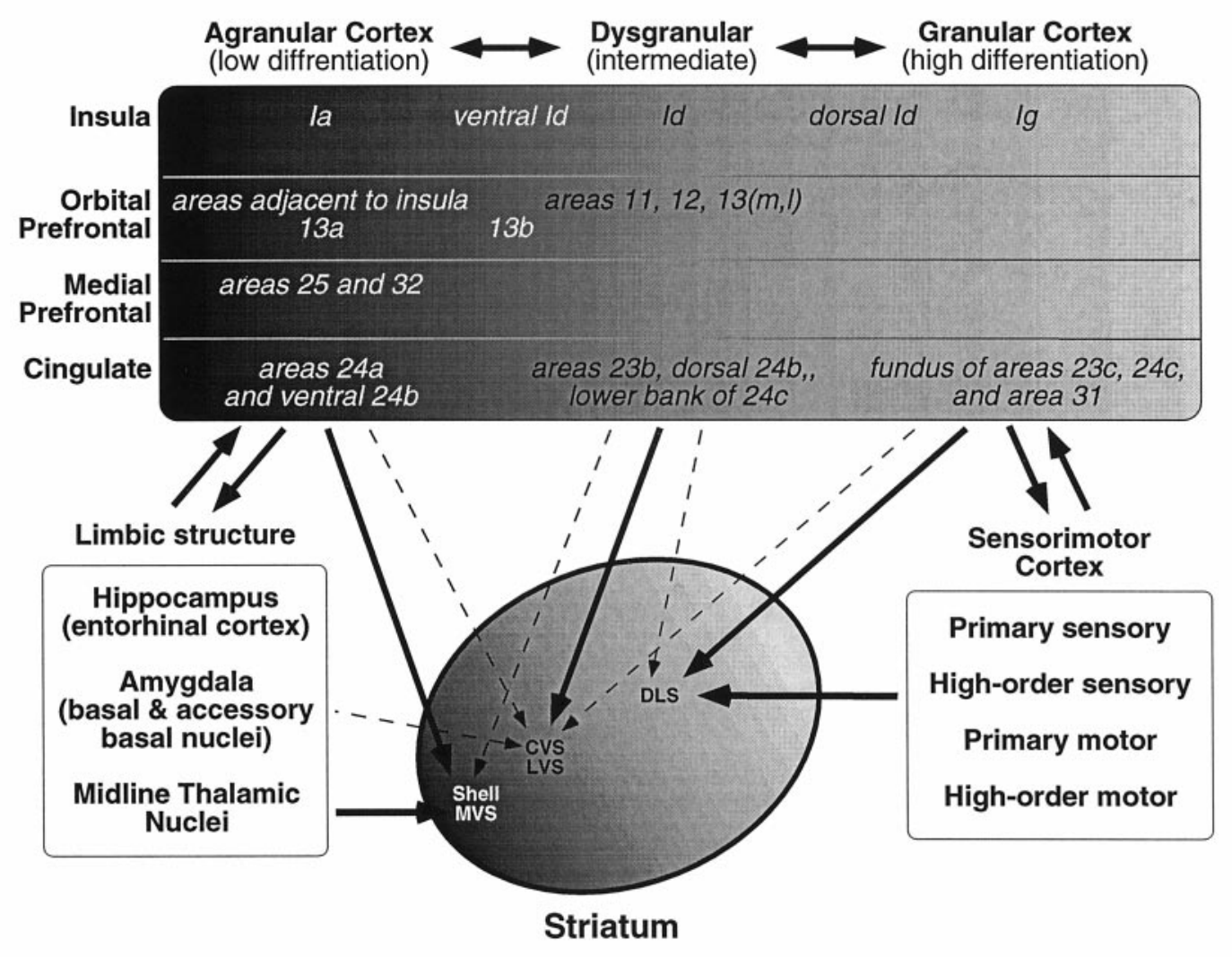

Figure 16. A, Summary diagram demonstrating the continuum of insular projections to the striatum. The gray gradients in both the insula and the striatum show the basic organization of insulostriatal projections from the different cytoarchitectonic regions of the insula. $B$, Graphical illustration of the insular, the cingulate, and the orbital and medial prefrontal cortical projections to the striatum. The top rectangle is filled with a gray gradient to indicate the cortical cytoarchitectonic differentiation in these cortical areas. Agranular cortices are placed in the dark portion, whereas granular cortices are placed in the light portion of this rectangle. Agranular cortices connect primarily with limbic structures and project to the medial and ventral portion of the ventral striatum. Cytoarchitectonically more differentiated (granular) cortices primarily have connections with sensorimotor cortices and project to the dorsolateral striatum $(D L S)$. Intermediate differentiated (dysgranular) cortices primarily project to the central ventral striatum $(C V S)$ and the lateral ventral striatum $(L V S)$. Bold arrows represent major projections. Dotted arrows show minor projections. POC, Piriform olfactory cortex; SLS, superior limiting sulcus; $I L S$, inferior limiting sulcus; $M V S$, medial ventral striatum. 
posterior Ig projects to the dorsal part of the dorsolateral striatum (case MS56). These striatal regions receive primary somatosensory input from hand and face areas and leg and arm areas, respectively (Künzle, 1975; Jones et al., 1977; Flaherty and Graybiel, 1991). Thus, Ig and the adjacent Id send somatosensory information to the dorsolateral striatum, and these projections are somatotopically organized.

\section{Gustation: an integrative look at the function of insulostriatal projections}

The primary cortical gustatory area in the monkey is located within the fundus of the superior limiting sulcus (SLS) and includes part of the adjoining anterior insula (Bagshaw and Pribram, 1953; Benjamin and Burton, 1968; Sudakov et al., 1971; Pritchard et al., 1986; Scott et al., 1986). Within the insula, gustatory responses can be elicited specifically in the anterior and central portions of Id (Yaxley et al., 1990; SmithSwintosky et al., 1991). This gustatory-related insular region projects primarily to the central ventral striatum (cases MS49 and M8-93). In addition to the dorsal portion of Id that receives somatosensory information regarding the hand and face, Ia and the ventral portion of Id, which are involved in olfactory and autonomic functions, also project partially to central ventral striatum (case MS49) (Mesulam and Mufson, 1993). Anatomical and physiological studies suggest that the anterior Ig and adjacent Id may contribute to tactile object recognition in the hand and mouth associated with feeding behavior (Friedman et al., 1986; Preuss and Goldman-Rakic, 1989). Thus, projections to central ventral striatum from the "gustatory" insular region (Id) and adjacent regions of Ia and Ig may provide a wide spectrum of information regarding food acquisition with respect to olfactory, autonomic, gustatory, and somatosensory functions. Convergence of these insular inputs in the central ventral striatum may provide contexts for activation of basal ganglia circuits involved in feeding behaviors.

\section{REFERENCES}

Aggleton JP, Burton MJ, Passingham RE (1980) Cortical and subcortical afferents to the amygdala of the rhesus monkey. Brain Res 190:347-368.

Alheid GF, Heimer L, Switzer RC (1990) Basal ganglia. In: The human nervous system (Paxinos G, ed), pp 483-582. San Diego: Academic.

Amaral DG, Price JL (1983) An air pressure system for the injection of tracer substances into the brain. J Neurosci 9:35-43.

Amaral DG, Price JL (1984) Amygdalo-cortical projections in the monkey (Macaca fascicularis). J Comp Neurol 230:465-496.

Bagshaw MH, Pribram KH (1953) Cortical organization in gustation. J Neurophysiol 16:499-508.

Baleydier C, Mauguiere F (1980) The duality of the cingulate gyrus in monkey: neuroanatomical study and functional hypothesis. Brain 103:525-554.

Barbas H (1992) Architecture and cortical connections of the prefrontal cortex in the rhesus monkey. In: Advances in neurology (Chauvel P, Delgado-Escueta AV, eds), pp 91-115. New York: Raven.

Barbas H, Pandya DN (1989) Architecture and intrinsic connections of the prefrontal cortex in the rhesus monkey. J Comp Neurol 286:353-375.

Benjamin RM, Burton H (1968) Projection of taste nerve afferents to anterior opercular-insular cortex in squirrel monkey. Brain Res 7:221-231.

Berthier M, Starkstein S, Leiguarda R (1988) Asymbolia for pain: a sensory-limbic disconnection syndrome. Ann Neurol 24:41-49.

Butter CM (1969) Perseveration in extinction and in discrimination reversal tasks following selective frontal ablations in Macaca mulatta. Physiol Behav 4:163-171.

Carmichael ST, Price JL (1994) Architectonic subdivision of the orbital and medial prefrontal cortex in the macaque monkey. J Comp Neurol 346:366-402.

Carmichael ST, Price JL (1996) Limbic connections of the orbital and medial prefrontal cortex in macaque monkeys. J Comp Neurol 363:615-641.

Carmichael ST, Clugnet MC, Price JL (1994) Central olfactory connections in the macaque monkey. J Comp Neurol 346:403-434.

Casey KL, Minoshima S, Berger KL, Koeppe RA, Morrow TJ, Frey KA (1994) Positron emission tomographic analysis of cerebral structures activated specifically by repetitive noxious heat stimuli. J Neurophysiol 71:802-807.

Cowan WM, Gottlieb DI, Hendrickson A, Price JL (1972) The autoradiographic demonstration of axonal connections in the central nervous system. Brain Res 37:21-51.

Dum RP, Strick PL (1993) Cingulate motor areas. In: Neurobiology of cingulate cortex and limbic thalamus: a comprehensive treatise (Vogt BA, Gabriel M, eds), Boston: Birkhauser.

Flaherty AW, Graybiel AM (1991) Cortical transformations in the primate somatosensory system. Projections from physiologically mapped body-part representations. J Neurophysiol 66:1249-1263.

Friedman DP, Murray EA, O’Neill JB, Mishkin M (1986) Cortical connections of the somatosensory fields on the lateral sulcus of macaques: evidence for a corticolimbic pathway for touch. J Comp Neurol 252:323-347.

Giménez-Amaya JM, McFarland NR, de las Heras S, Haber SN (1995) Organization of thalamic projections to the ventral striatum in the primate. J Comp Neurol 354:127-149.

Greenspan JD, Winfield JA (1992) Reversible pain and tactile deficits associated with a cerebral tumor compressing the posterior insula and parietal operculum. Pain 50:29-39.

Haber SN, Lynd E, Klein C, Groenewegen HJ (1990) Topographic organization of the ventral striatal efferent projections in the rhesus monkey: an anterograde tracing study. J Comp Neurol 293:282-298.

Haber SN, Lynd-Balta E, Spooren WPTM (1994) Integrative aspects of basal ganglia circuitry. In: The basal ganglia. IV (Percheron G, McKenzie JS, Féger J, eds), pp 71-80. New York: Plenum.

Haber SN, Kunishio K, Mizobuchi M, Lynd-Balta E (1995) The orbital and medial prefrontal circuit through the primate basal ganglia. J Neurosci 15:4851-4867.

Hemphill M, Holm G, Crutcher M, Delong M, Hedreen J (1981) Afferent connections of the nucleus accumbens in the monkey. In: The neurobiology of the nucleus accumbens (Chronister RB, DeFrance JF, eds), pp 75-81. Brunswick, ME: Hear Institute.

Herzog AG, Van Hoesen GW (1976) Temporal neocortical afferent connections to the amygdala in the rhesus monkey. Brain Res 115:57-69.

Hoffman BL, Rasmussen T (1953) Stimulation studies of insular cortex of Macaca mulatta. J Neurophysiol 16:343-351.

Insausti R, Amaral DG, Cowan WM (1987) The entorhinal cortex of the monkey. II. Cortical afferents. J Comp Neurol 264:356-395.

Jones EG, Coulter JD, Burton H, Porter R (1977) Cells of origin and terminal distribution of corticostriatal fibers arising in the sensorymotor cortex of monkeys. J Comp Neurol 173:53-80.

Kaada BR, Pribram KH, Epstein JA (1949) Respiratory and vascular responses in monkeys from temporal pole, insula, orbital surface and cingulate gyrus. J Neurophysiol 12:348-356.

Kunishio K, Haber SN (1994) Primate cingulostriatal projection: limbic striatal versus sensorimotor striatal input. J Comp Neurol 350:337-356.

Künzle H (1975) Bilateral projections from precentral motor cortex to the putamen and other parts of the basal ganglia. An autoradiographic study in Macaca fascicularis. Brain Res 88:195-209.

Martin LJ, Hadfield MG, Dellovade TL, Price DL (1991) The striatal mosaic in primates: patterns of neuropeptide immunoreactivity differentiate the ventral striatum from the dorsal striatum. Neuroscience 43:397-417.

Meredith GE, Pattiselanno A, Groenewegen HJ, Haber SN (1996) Shell and core in monkey and human nucleus accumbens identified with antibodies to calbindin-D28k. J Comp Neurol 365:628-639.

Mesulam M-M, Mufson EJ (1982a) Insula of the Old World monkey. I. Architectonics in the insulo-orbito-temporal component of the paralimbic brain. J Comp Neurol 212:1-22.

Mesulam M-M, Mufson EJ (1982b) Insula of the Old World monkey. III. Efferent cortical output and comments on function. J Comp Neurol 212:38-52.

Mesulam M-M, Mufson EJ (1993) The insula of reil in man and monkey. 
In: Cerebral cortex (Peters A, Jones EG, eds), pp 179-225. New York: Plenum.

Moldonado-Irizarry CS, Swanson CJ, Kelley AE (1995) Glutamate receptors in the nucleus accumbens shell control feeding behavior via the lateral hypothalamus. J Neurosci 15:6779-6788.

Morecraft RJ, Van Hoesen GW (1992) Cingulate input to the primary and supplementary motor cortices in the rhesus monkey: evidence for somatotopy in areas 24c and 23c. J Comp Neurol 322:471-489.

Morecraft RJ, Geula C, Mesulam M-M (1992) Cytoarchitecture and neural afferents of orbitofrontal cortex in the brain of the monkey. J Comp Neurol 323:341-358.

Mufson EJ, Mesulam M-M (1982) Insula of the Old World monkey. II. Afferent cortical input and comments on the claustrum. J Comp Neurol 212:23-37.

Penfield W, Faulk ME (1955) The insula: further observations on its function. Brain 78:445-470.

Preuss TM, Goldman-Rakic PS (1989) Connections of the ventral granular frontal cortex of macaques with perisylvian and somatosensory areas: anatomical evidence for somatic representation in primate frontal association cortex. J Comp Neurol 282:293-316.

Pritchard TC, Hamilton RB, Morse JR, Norgren R (1986) Projections of thalamic gustatory and lingual areas in the monkey. J Comp Neurol 244:213-228.

Robinson CL, Burton H (1980) Somatic submodality distribution within the second somatosensory (S11), 7b, retroinsular, post-auditory and granular insular cortical areas of M. fascicularis. J Comp Neurol 192:93-108.

Rose M (1928) Die Inselrinde Des Menschen und Der Tiere. J Psychol Neurol 37:467-624.

Russchen FT, Bakst I, Amaral DG, Price JL (1985) The amygdalostriatal projections in the monkey. An anterograde tracing study. Brain Res 329:241-257.

Schneider RJ, Friedman DP, Mishkin M (1993) A modality-specific somatosensory area within the insula of the rhesus monkey. Brain Res 621:116-120.

Scott TR, Yaxley S, Sienkiewicz ZJ, Rolls ET (1986) Gustatory re- sponses in the frontal opercular cortex of the alert cynomolgus monkey. J Neurophysiol 56:876-890.

Selemon LD, Goldman-Rakic PS (1985) Longitudinal topography and interdigitation of corticostriatal projections in the rhesus monkey. J Neurosci 5:776-794.

Showers MJC, Lauer EW (1961) Somatovisceral motor patterns in the insula. J Comp Neurol 117:107-116.

Smith-Swintosky VL, Plata-Salaman CR, Scott TR (1991) Gustatory neural coding in the monkey cortex: stimulus quality. J Neurophysiol 66:1156-1165.

Sudakov K, MacLean PD, Reeves A, Marino R (1971) Unit study of exteroceptive inputs to claustrocortex in awake, sitting, squirrel monkey. Brain Res 28:19-34.

Suddath RL, Christison GW, Torrey EF, Casanova MF, Weinberger DR (1990) Anatomical abnormalities in the brains of monozygotic twins discordant for schizophrenia. N Engl J Med 322:789-794.

Szabo J, Cowan WM (1984) A stereotaxic atlas of the brain of the cynomolgus monkey. J Comp Neurol 222:265-300.

Van Hoesen GW, Yeterian EH, Lavizzo-Mourney R (1981) Widespread corticostriate projections from temporal cortex of the rhesus monkey. J Comp Neurol 199:205-219.

Van Hoesen GW, Morecraft RJ, Vogt BA (1993) Connections of the monkey cingulate cortex. In: Neurobiology of cingulate cortex and limbic thalamus: a comprehensive treatise (Vogt BA, Gabriel M, eds), pp 249-284. Boston: Birkhauser.

Vogt BA, Pandya DN, Rosene DL (1987) Cingulate cortex of the rhesus monkey. I. Cytoarchitecture and thalamic afferents. J Comp Neurol 262:256-270.

Yaxley S, Rolls ET, Sienkiewicz ZJ (1990) Gustatory responses of single neurons $i$ the insula of the macaque monkey. J Neurophysiol 63:689-700.

Yeterian EH, Pandya DN (1991) Prefrontostriatal connections in relation to cortical architectonic organization in rhesus monkeys. J Comp Neurol 312:43-67.

Yeterian EH, Pandya DN (1993) Striatal connections of the parietal association cortices in rhesus monkeys. J Comp Neurol 332:175-197. 